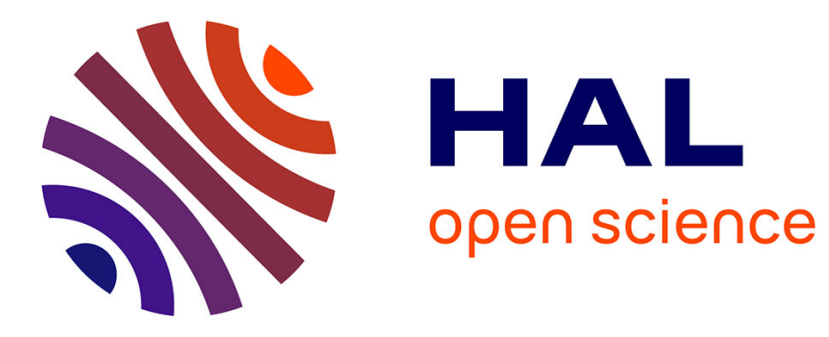

\title{
Spectral Emissivity of Phonolite Lava at High Temperature
}

Hao Li, Joan Andujar, Aneta Slodczyk, Domingos de Sousa Meneses, Bruno Scaillet, Patrick Echegut, Jonas Biren, Clive Oppenheimer

\section{To cite this version:}

Hao Li, Joan Andujar, Aneta Slodczyk, Domingos de Sousa Meneses, Bruno Scaillet, et al.. Spectral Emissivity of Phonolite Lava at High Temperature. IEEE Transactions on Geoscience and Remote Sensing, 2022, 60, pp.1-15. 10.1109/TGRS.2021.3104657 . insu-03433900

\section{HAL Id: insu-03433900 https://hal-insu.archives-ouvertes.fr/insu-03433900}

Submitted on 18 Nov 2021

HAL is a multi-disciplinary open access archive for the deposit and dissemination of scientific research documents, whether they are published or not. The documents may come from teaching and research institutions in France or abroad, or from public or private research centers.
L'archive ouverte pluridisciplinaire HAL, est destinée au dépôt et à la diffusion de documents scientifiques de niveau recherche, publiés ou non, émanant des établissements d'enseignement et de recherche français ou étrangers, des laboratoires publics ou privés. 


\title{
Spectral emissivity of phonolite lava at high temperature
}

\author{
Hao Li, Joan Andújar, Aneta Slodczyk, Domingos De Sousa Meneses, Bruno Scaillet, Patrick \\ Echegut, Jonas Biren, Clive Oppenheimer
}

\begin{abstract}
The rheology and thermodynamical evolution of magma, either in reservoirs, conduits or at the surface, are governed by temperature. To determine the field temperature, remote sensing methods based on measuring the infrared radiance are widely applied, but they are subject to assumptions and caveats that can propagate into large uncertainties. This is related to the poor knowledge of one of the most critical parameters, namely the spectral emissivity. In this work we aim at filling this gap through in situ spectral emissivity measurements performed over wide temperature (700-1600 $\mathrm{K})$ and spectral ranges $(1.25-25$ $\mu \mathrm{m})$ on two representative phonolitic compositions from Erebus (Antartica) and Teide (Spain) volcanoes. The laboratory spectra allow to determine precisely spectral emissivity in the thermal infrared (TIR), middle infrared (MIR), and shortwave infrared (SWIR) ranges. The results reveal the complexity and contrasted behavior of the radiative properties of the two rocks melts, despite their broadly similar composition. The spectral emissivity varies significantly as a function of temperature, composition, crystallinity, thickness, and thermal history. Altogether, the data reveal that emissivity cannot be considered as a constant value and question previous arguments that active lava always has lower emissivity than frozen lava. Finally, the laboratory-measured values of spectral emissivity were used to refine the temperature of Erebus lava lake gathered from previous remote sensing methods.
\end{abstract}

Index Terms - Emissivity, phonolite lava, radiative transfer, remote sensing, temperature measurement, thermal infrared.

\section{INTRODUCTION}

$\mathrm{T}$ EMPERATURE is one of the most important intensive parameters that influences the rheology and thermodynamical evolution of magma, whether below the surface in reservoirs and conduits or at the surface during eruption. Although temperatures are well controlled at the laboratory, precise field determinations of lava temperature using contact methods (e.g., thermocouples) are hazardous or impractical (e.g., due to access limitations or high yield strength and viscosity) and relatively few good observations have been made in this way. Pre-eruptive temperatures can be retrieved by analysis of volcanic products (rocks, minerals) [1], but these

This work is part of H.Li PhD thesis funded by CNRS, French science ministery, Labex Voltaire, ANR-LABX-100-01, Equipex Planex ANR-11EQPX-36 and by TelluS program of CNRS/INSU with RADIABAR project.

H. Li, J. Andújar, A. Slodczyk, B. Scaillet, J. Biren are with the Institut des Sciences de la Terre d'Orléans (ISTO), UMR 7327, CNRS/BRGM, Université d’Orléans, F-45071, Orléans, France (e-mail: hao.li@univ-orleans.fr). may not reflect eruption temperatures. Remote sensing methods based on measuring the infrared (IR) radiance from active lava bodies are widely applied, using spaceborne, airborne or ground-based platforms [2]. However, they are subject to assumptions and caveats that can propagate large uncertainties $( \pm 100 \mathrm{~K})$ related to the surrounding environment [3], [4], large temperature gradients of cooling lavas as well as constant changes in their composition and texture during emplacement. Despite that reducing the uncertainties of environmental and thermal gradients when measuring emissivity is ultimately challenging, this study is aimed at minimizing the uncertainty of one of the critical, yet poorly known, parameters namely spectral emissivity $\left(\varepsilon_{\lambda}\right)$. This parameter is crucial to invert remotely-sensed spectral radiance observations of lava at high $\mathrm{T}$, including in the molten state. Only a few laboratory studies have been carried out on this topic, highlighting the technical difficulties for obtaining accurate emissivity data, especially at high temperature [4]-[14].

In addition, most of them have been performed on crystals or synthetic glass compositions at temperatures $(\mathrm{T})$ below the glass transition $(\mathrm{Tg})$, and over limited spectral range (typically the 6-14 $\mu \mathrm{m}$ thermal IR, i.e., TIR band) [6], [13], [15]. Much of this work has been motivated by interest in structural modifications affecting the probed material (phase transitions, melting), the degree of polymerization of network (model $\mathrm{Q}_{\mathrm{n}}$ of silicates) [16]-[18] or chemical composition (e.g., Si content, nonbridging oxygens per tetrahedrally-coordinated cations, i.e., $\mathrm{NBO} / \mathrm{T}$ ). For remotely sensed temperature estimates made in the TIR, a number of studies have recommended characterization of emissivity across a wider spectral region [4], [12], [13]. Spectral emissivity at high temperatures is also pertinent for modelling the heat exchange between gas and melt in ascending magmas [19].

Given the limited experimental constraints on emissivity, the default approach is to use an average [7], wideband constant emissivity for a given volcanic rock family, for example, 0.9 for basalts. In order to minimise errors of satellite-based measurements of land surface temperature, different algorithms (e.g., TES: Temperature Emissivity Separation method) have been developed to retrieve information on both temperature and

H. Li, A. Slodczyk, D. D. S. Meneses, P. Echegut are with the CNRS, CEMHTI UPR3079, University Orléans, F-45071 Orléans, France.

C. Oppenheimer is with the Department of Geography, University of Cambridge, Downing Place, Cambridge, CB2 3EN, UK. 
emissivity [20]. Such a procedure is complex due to the nonlinear and complex relationship between these two parameters $[21,22]$, requiring assumptions to be made about the nature of the relationship between the variables [22]. However, as our knowledge about emissivity is still quite limited, this may lead to poorly constrained emissivity-based temperatures.

At magmatic temperatures, a $10 \%$ uncertainty in emissivity $(7.5-13 \mu \mathrm{m})$ propagates to a temperature uncertainty of order $\approx 80 \mathrm{~K}$ [23]. This is significant because temperature change of this magnitude for a basalt may result in substantial rheological changes [8], [24], with important implications for flow dynamics, and the application of thermo-rheological models used in hazard assessment [11], [13]. For instance, Rogic et al. [13] have shown that a change in average emissivity from 0.8 to 1 produces a $600 \mathrm{~m}$ difference of the calculated lava flow runout at Etna volcano. Additional complexity arises from the multiphase nature of lavas, each constitutive phase having a specific contribution to the spectral emissivity [25]. Whereas spectral emissivities for various minerals/crystals have been recorded [6], [8], [26], [27], most measurements were made at low temperature (i.e., below the glass transition temperature). We do not know how well they might represent lava surfaces at eruptive temperatures. As a result, the functional relationship between temperature and emissivity of magmatic rocks still needs to be firmly established [13], [28].

As a further example of the problem, we consider the persistent lava lake of Erebus volcano (Antarctica), which has been the focus of detailed studies of heat and gas emissions [29]. Despite its remoteness, the longevity of the lava lake, proximity of the volcano to McMurdo station and aspects of the prevailing environmental conditions (e.g., low atmospheric humidity, low elevation or absent Sun, [29], [30]) make Erebus a promising target for infrared radiometry [31], [32], yielding data that can be compared with other approaches [29], [33][35]. The temperature estimates reported in these studies vary widely, however (from 1073 up to $1373 \mathrm{~K}$ ), illustrating the enduring challenge of measuring one of the most fundamental attributes of volcanism.

The aims of this work are to make a contribution to bridging this gap through in situ spectral emissivity measurements of relevant volcanic rocks. We focus on phonolitic compositions, using natural samples from Erebus and Teide (Canary Islands, Spain). The laboratory spectra presented below were recorded over wide temperature $(500-1600 \mathrm{~K})$ and spectral $(1-25 \mu \mathrm{m})$ ranges. This spectral range spans the thermal infrared (TIR: 8$15 \mu \mathrm{m}$ ), middle infrared (MIR: 3-6 $\mu \mathrm{m}$ ), and shortwave infrared (SWIR: 1-3 $\mu \mathrm{m}$ ) bands, all of which have been used for radiometry and thermometry of active lava bodies using data from airborne/satellite and ground-based instruments. Owing to the nonlinearity in the Planck function, the SWIR is especially suited for monitoring high temperature features [36]-[38]. However, it should be stressed that most of the geological samples become semi-transparent in this spectral region and thus the contribution of the inner thermal gradient to recorded heat flux from the volume/thickness can be important (see Discussion). Our experimental results enable us to explore the variation of spectral emissivity with temperature, composition, crystallinity and thermal history. Drawing on our findings, we reassess the temperature of the Erebus lava lake.

\section{MATERIALS AND METHODS}

\section{A. Sample selection}

We have used two phonolite compositions from Erebus and Teide volcanoes. Phonolites are the end-members of alkali-rich magmatic series, that sometimes may produce extremely explosive eruptions (e.g., the Tambora 1815 eruption). Our parallel studies on these two phonolites give insights into the impacts of small variation in composition on the emissivitytemperature relationship. Erebus and Teide compositions are similar to that of other phonolitic centers (including the Campi Flegrei-Vesuvius in Italy, Eiffel volcanic complex in Germany, or Tambora in Indonesia), sharing the same $\mathrm{SiO}_{2} / \mathrm{Na}_{2} \mathrm{O}+\mathrm{K}_{2} \mathrm{O}$ ratios. Overall, phonolitic magmas emitted worldwide show a compositional variation in terms of major oxides $(\mathrm{CaO}, \mathrm{MgO}$, $\mathrm{Al}_{2} \mathrm{O}_{3}, \mathrm{TiO}_{2}, \mathrm{FeO} *$ ) that falls between the poles defined by Teide and Erebus compositions [39]. Consequently, the expected radiative thermal response of other phonolites should lie in between those of Erebus and Teide. It should be noted that eruptions of the vast majority of phonolitic volcanoes have occurred before the development of remote sensing techniques and, consequently, radiative measurements are today available only for Erebus which hosts the sole active phonolitic lava lake so far identified.

The petrology and geochemistry of our Erebus phonolite sample have been reported in detail elsewhere [35]. The rock contains about $34 \mathrm{wt} \%$ phenocrysts with up to $30 \mathrm{wt} \%$ anorthoclase feldspar, $2 \mathrm{wt} \%$ Ti-magnetite, $1 \mathrm{wt} \%$ olivine, 0.6 wt\% clinopyroxene, and $0.4 \mathrm{wt} \%$ apatite. The whole assemblage is contained within a microlite-poor, highly vesiculated phonolitic glassy matrix. The exceptional crystal size (up to $7 \mathrm{~cm}$ ) of anorthoclase feldspar present in the Erebus phonolite allowed exploration of two additional effects: (i) the impact of the degree of polymerization/ordering and (ii) the effect of crystallographic orientation or anisotropy on the spectral emissivity of crystals/glasses.

The phonolite from the Teide volcano contains $\approx 14 \mathrm{wt} \%$ of phenocrysts of anorthoclase feldspar with minor amounts of biotite, Ti-magnetite, clinopyroxene, and ilmenite $(0.1 \mathrm{wt} \%)$. Phenocrysts are set in a highly crystalline groundmass consisting of microlites of alkali feldspar, magnetite, clinopyroxene, and glass [40]. Additionally, the petrography and pre-eruptive temperature, the latter inferred from phase equilibrium experiments [40], are well known for Teide.

\section{B. Preparation of the starting materials for spectral emissivity measurements}

Several pieces of the two phonolitic samples (Erebus and Teide) were (separately) finely ground in an agate mortar and then melted in a Pt crucible at $1673 \mathrm{~K}$ for $2 \mathrm{~h}$ in an open-air atmosphere. The melt was quenched in a water container and the recovered glass chips were ground and re-melted again for $2 \mathrm{~h}$ under the same conditions. Small pieces of the resulting starting glasses were embedded in Epoxy resin, polished and analyzed with the Cameca SXFive electron probe 
microanalyzer (EMPA) at ISTO. The analytical conditions were $20-\mu \mathrm{m}$-diameter defocused beam, $15 \mathrm{kV}$ and $6 \mathrm{nA}$ to ensure minimal alkali migration during analysis [40]. The average composition ( 40 analyses per sample) of each phonolite compares well with available bulk-rock data [35], [40], with no evidence of $\mathrm{Na}$ or Fe loss (Table 1). The Erebus and Teide samples differ primarily in their contents of $\mathrm{SiO}_{2}$ (up to $5 \mathrm{wt} \%$ ) and $\mathrm{FeO}^{*}$ (up to $2 \mathrm{wt} \%$, see Table 1, $\mathrm{FeO}^{*}$ : the entire $\mathrm{Fe}$ is represented in $\mathrm{FeO}$ ).

Each phonolitic glass was then drilled to obtain core cylinders of $10 \mathrm{~mm}$ diameter, which were cut into slices of thickness $1.7 \mathrm{~mm}$. Both sides of every single cut were polished to achieve optically-parallel surfaces and a total thickness of $1.5 \pm 0.1 \mathrm{~mm}$. This was done to optimise the response of the sample during the emissivity measurements [41].

In addition, anorthoclase crystals from the Erebus phonolite were cut in two different directions: one parallel and the other perpendicular to the main c-axis of the crystal. Both sections were polished following the same procedure as for glassy samples.

\section{In situ spectral emissivity measurements}

In order to determine the thermal radiative properties of a semi-transparent sample, two common procedures allow spectral emissivity measurements: (i) the direct method in which $\varepsilon$, is defined as the ratio of the spectral radiance emitted by the sample (L) to that emitted by a perfect blackbody $\left(\mathrm{L}^{0}\right)$ at the same temperature and identical geometrical conditions:

$\varepsilon_{\lambda}(\sigma, T, \theta)=L_{\lambda}(\sigma, T, \theta) / L_{\lambda}^{0}(\sigma, T, \theta)$

and (ii) the indirect method based on the second Kirchhoff's law in which $\varepsilon$ is derived from measurements of both spectral reflectance $(\rho)$ and spectral transmittance $(\tau)$ :

$\varepsilon_{\lambda}(\sigma, T, \theta)=1-\rho_{\lambda}(\sigma, T, \theta)-\tau_{\lambda}(\sigma, T, \theta)$

In the case of an opaque sample $(\tau=0)$, the reflectance is sufficient to determine $\varepsilon$. Both methods have advantages and drawbacks [42], [43], and have been applied to study the radiative properties of geological materials [7].

Our approach involved the direct method using a high potential apparatus (Fig.1) allowing emissivity measurements under extreme temperature conditions (up to $2500 \mathrm{~K}$ ) and, thanks to the installation of multiple detectors and beam splitters in the spectrometers, over a very wide spectral range (20-12500 $\mathrm{cm}^{-1}$, approx. 0.8-500 $\left.\mu \mathrm{m}\right)$ [41], [43], [44]. This range covers the TIR, MIR, and SWIR bands used by various remote sensing instruments such as ASTER (Advanced Spaceborne Thermal Emission and Reflection Radiometer), MODIS (Moderate Resolution Imaging Spectroradiometer), ALI (Advanced Land Imager), HyTES (Hyperspectral Thermal Emission Spectrometer), and MIROVA (Middle InfraRed Observation of Volcanic Activity) [7], [15], [20], [38].

To ensure a homogeneous temperature distribution, the sample was placed on a refractory ceramic plate and heated above and below using a $500 \mathrm{~W} \mathrm{CO}_{2}$ laser (Diamond $\mathrm{K} 500$, Coherent Inc.). The use of a $\mathrm{CO}_{2}$ laser avoided interferences that arise when standard external furnaces are used to measure $\varepsilon$. In our case, the characteristic $\mathrm{CO}_{2}$ laser emission at $10.6 \mu \mathrm{m}$ can be easily identified and eliminated from the signal, ensuring that recorded $\varepsilon$ corresponds only to that of the sample. A PYROX PY8 furnace with a lanthanum chromite cylindrical cavity and $8 \mathrm{~mm}$ aperture was used as a reference blackbody. To increase system stability, the blackbody furnace was maintained at a constant temperature of $1273 \mathrm{~K}$.

The sample and the blackbody furnace were placed on a motorized turntable inside a dry-air purged chamber. The thermal radiant fluxes of the sample and blackbody were collected simultaneously by two Fourier transform infrared (FTIR) spectrometers placed face-to-face on each side of the purged chamber: i) a Bruker Vertex $70\left(\mathrm{Vis} / \mathrm{CaF}_{2}\right.$ beam splitter, InGaAs detector, resolution $4 \mathrm{~cm}^{-1}$ ) and ii) a Bruker Vertex $80 \mathrm{v}$ (Ge/KBr beam splitter, DLaTGS/KBr detector, resolution $4 \mathrm{~cm}^{-}$ $\left.{ }^{1}\right)$. The turntable permitted FTIR spectra to be collected in pairs: the first spectrometer recorded the spectrum of the sample while the second recorded that of the reference and vice versa. This configuration guarantees the same simple optical path whereas covering such a wide spectral range. In order to eliminate interferences from the apparatus environment itself, measurements of the ambient background were also recorded.

The experimental procedure is then based on the three radiance measurements: sample (s), blackbody (b), and ambient (a), and the following equation permits calculation of the spectral emissivity of the sample:

$\varepsilon=\left[F T\left(I_{s}-I_{a}\right) / F T\left(I_{b}-I_{a}\right)\right] *\left[\left(B_{b}^{0}-B_{a}^{0}\right) /\left(B_{s}^{0}-B_{a}^{0}\right)\right]$ (3)

where $F T$ indicates Fourier transform, $I$ is the interferogram (s, b, a represent the sample, blackbody, and ambient, respectively), $B$ is the Planck function. Since the temperature of blackbody is precisely calibrated [44], ambient temperature remains constant, the error of $\varepsilon$ determination is only related to sample temperature. Note, the exact sample temperature is not set but, is precisely calculated (accuracy $>99 \%$ ) during the measurement using the Christiansen wavenumber or Christiansen feature (CF) [42], [44], [45], [46]. The CF is an intrinsic material property present in various polar dielectric substances [42], [45], defined as the wavelength at which the sample behaves as blackbody $(\varepsilon=1)$. At this value, the spectrometer works as a monochromatic pyrometer and then, according to Planck's law, the temperature can be readily determined [43], [47]. The standard uncertainty for the computed emissivity is estimated to be around $2 \%$, and the standard uncertainty in the determination of the material temperature is estimated to be less than $1 \%$.

The spectra were collected during both heating and cooling, in the temperature range $570 \mathrm{~K}$ to $1600 \mathrm{~K}$ (i.e., below to above the liquidus). In order to maintain the sample geometry and flatness during emissivity measurements, which are important parameters controlling both the quality and reliability of infrared measurements, most of the spectra were recorded during heating. The direct method is somewhat restricted below $500 \mathrm{~K}$ owing to the lower emittance of the sample and weaker signal to noise ratio with particular impacts in the MIR and SWIR regions. The $\mathrm{CO}_{2}$ laser induces a very rapid and homogenous heating. Infrared camera measurements show that the sample area over which the temperature can be considered as homogeneous is $4 \mathrm{~mm}$ in diameter. Additionally, the setting of the spectrometer diaphragm to $1 \mathrm{~mm}$ ensures that the 
recorded spectral radiance was sourced from a $2 \mathrm{~mm}$ circular spot in the center of the sample.

During cooling experiments, two different cooling rates were used: a slow rate $(\approx 10 \mathrm{~K} / \mathrm{min})$ aimed at simulating cooling of active lava flows [48]-[53] and a fast rate more representative of the cooling of a volcanic bomb during its trajectory in air. The fast rate was affected by switching off the laser. For heating or slow cooling, the laser power was simply increased or decreased as required.

\section{RESULTS}

A. The effect of composition on radiative properties: spectral emissivity of Teide and Erebus samples

Fig. 2 compares the temperature evolution of spectral emissivity for Teide and Erebus samples: panels a and b show the full spectral range investigated (TIR-MIR-SWIR), whereas panels $\mathrm{c}$ and $\mathrm{d}$ focus on TIR, the range most widely used in observations [7], [8], [10], [11], [13], [14].

The typical broadband spectral emissivity of a dielectric material can be divided into three spectral regions: the first, below $1500 \mathrm{~cm}^{-1}$, the so-called opaque region (covering the TIR) that reveals the lattice vibrations of the main structure network; the second, above $1500 \mathrm{~cm}^{-1}$ (MIR) assigned to multiphonon processes, and the third at high wavenumbers (SWIR), related to electronic processes [43], [54]. Note that, in the MIR and SWIR regions, most of the samples show rather semi-transparent behaviour. Consequently, the radiative properties are proper of volume (dependent on an optical thickness, hence on the absorption coefficient [55]), in contrast to the TIR region which reflects the surface properties exclusively.

At low frequencies, characteristic of the silicate network, the spectral emissivities of Teide and Erebus glasses are very similar. The presence of broad bands, in particular the characteristic reststrahlen band [41], reveals the vibrations of $\mathrm{Si}$ and/or Al-based tetrahedra of the disordered glass structure [16, 17]. As shown in Fig. 2c and 2d, both samples exhibit the CF at $1250 \mathrm{~cm}^{-1}$ for Teide and $1230 \mathrm{~cm}^{-1}$ for Erebus. The evolution of emissivity with temperature is very similar for both phonolites: it increases progressively as temperature increases, especially in the TIR region, between 900 and $1200 \mathrm{~cm}^{-1}$. Such a behaviour is very similar to that observed in pure silica [43], and can be explained by the increased dampening of the vibrations of the glass structure owing to the rise in anharmonicity due to temperature increase. Note that in the case of the Erebus sample, the small spectral modifications observed above $1300 \mathrm{~K}$ are related to local structure reorganization [9].

In contrast, above $2000 \mathrm{~cm}^{-1}$, the radiative properties of Teide and Erebus samples differ markedly. With a temperature increase from $764 \mathrm{~K}$ to $1413 \mathrm{~K}$, the Teide sample behaves very similarly to pure silica [43], with the transmission front shifting to higher wavenumbers and emissivity increasing by $\approx 0.05$ (Fig. 2a). Both phenomena are related to the strengthening of multiphonon processes. As it can be seen, the Teide exhibits a semi-transparent behaviour with a mean emissivity value of 0.35 at $4000 \mathrm{~cm}^{-1}$. It should be stressed that these emissivity evolutions are the ones measured for a sample thickness of 1.5 $\mathrm{mm}$ (see discussion). Near $3600 \mathrm{~cm}^{-1}$, the absorption peak associated with hydroxyl groups or water molecules dissolved in the glassy/liquid matrix is well identified [9]. At higher wavenumbers (above $4000 \mathrm{~cm}^{-1}$ ), the emissivity increase is related to the widening of the absorption bands of iron $\left(\mathrm{Fe}^{2+}\right.$ having a strong absorption band at $\approx 10000 \mathrm{~cm}^{-1}$ and a weaker one at $\approx 4500 \mathrm{~cm}^{-1}[56]$. The presence of $\mathrm{Fe}^{2+}$ absorption bands also explains the higher emissivity at $8000 \mathrm{~cm}^{-1}$ (e.g., at 1413 $\mathrm{K}, \varepsilon=0.58$ ) than at $4000 \mathrm{~cm}^{-1}$ (e.g., at $1413 \mathrm{~K}, \varepsilon=0.34$ ) [9].

As shown in Fig. 2b, the Erebus phonolite reveals a different emissivity behaviour above $2000 \mathrm{~cm}^{-1}$. Emissivity increases significantly up to $1185 \mathrm{~K}$, being close to unity (i.e., opacification phenomenon) in the range of $1200-8000 \mathrm{~cm}^{-1}$. Taking into account that the opacification process appears to be thermally activated, the origin of this behavior can be explained by the modifications of $\mathrm{Fe}$ redox state and/or the polaronic absorbance, as has been observed for some oxides such as $\mathrm{MgO}$ [42], [45]. Our in situ XRD measurements [9] allow us to relate it also with the changes of the local structure due to the iron clustering, i.e., the presence of an iron-based substructure. However, taking into account that the opacification process appears to be thermally activated, possible explanations include the modifications of the local structure due to the iron clustering and/or modifications of $\mathrm{Fe}$ redox state as well as polaronic absorbance, as has been observed in some oxides such as $\mathrm{MgO}$ [42]. This high emissivity is maintained until $1300 \mathrm{~K}$. With further temperature increase, the $\varepsilon$ decreases significantly achieving a rather constant value of 0.7 above $3000 \mathrm{~cm}^{-1}$ at molten lava $\mathrm{T}$.

These results show clearly that emissivity varies as a function of temperature and wavenumber (or wavelength), in addition to composition [57]. The emissivity of the Teide sample shows an important evolution as a function of wavenumber but remains at a relatively constant value with increasing temperature (Fig. 2b). In contrast, for Erebus, the evolution of emissivity is both temperature and wavenumber dependent, in particular above $1000 \mathrm{~cm}^{-1}$. These contrasted patterns demonstrate that even very small composition changes can lead to substantial emissivity differences.

\section{B. The effect of thermal history (slow cooling vs. quench) on radiative properties - the case of Erebus}

Two different cooling rates were tested in our experiments in an effort to simulate cooling common during lava flow $(\approx 10$ $\mathrm{K} / \mathrm{min}$, from $1543 \mathrm{~K}$ to $740 \mathrm{~K}$ ) and volcanic bomb quenching $\left(\mathrm{CO}_{2}\right.$ laser cut off, from super liquidus conditions, $\left.1608 \mathrm{~K}\right)$. As it can be seen in Fig. 3, Erebus sample displays radiative properties that change significantly with cooling rate.

Fig. 3a/c compares the emissivity spectra of the Erebus sample in its initial state, i.e., at the beginning of heating, and after either slow and fast cooling. In the low wavenumber range, including the TIR waveband, no differences of spectral emissivity are recorded with changes in cooling rate (Fig. 3c). However, above $2000 \mathrm{~cm}^{-1}$ the emissivity behaviour is surprisingly complex. The emissivity spectrum recorded at 737 $\mathrm{K}$ after fast cooling is very similar to that recorded at the 
beginning of heating $(760 \mathrm{~K})$. On the contrary, the data acquired after slow cooling $(740 \mathrm{~K})$ are significantly different. Namely, the emissivity achieves very high and constant value of 0.95 over the whole spectral range $\left(2000-6000 \mathrm{~cm}^{-1}\right)$. To understand this opacification phenomenon (also present during heating, see Fig. 2b), Fig. 3b/d shows in detail the emissivity change during the slow cooling from liquid $(1543 \mathrm{~K})$ to glassy state $(740 \mathrm{~K})$. At the highest temperatures (1543-1183 K), emissivity is constant, averaging 0.7 above $3000 \mathrm{~cm}^{-1}$. Below $1183 \mathrm{~K}$, opacification occurs, being manifested by the very rapid increase of emissivity from 0.7 to 0.98 . Such high values in the MIR and SWIR wavebands are maintained with further temperature decrease. These results show clearly that around $950 \mathrm{~K}$ important changes occur in the sample structure, both during heating or cooling, giving rise to significantly higher emissivity. In order to remove the imprint of this new structural/chemical organization, the sample must be remelted. When the quench is performed above $1600 \mathrm{~K}$, the sample recovers its initial state. The slow cooling thus leads to structural/chemical modifications whereby the sample acquires unique radiative properties similar to that of a blackbody once in the low temperature range.

\section{The effect of crystals on radiative properties: insight from} Erebus anorthoclase

Here, we compare the spectral emissivity of the Erebus glass (Fig.2b, 2d) with measurements obtained on two Erebus anorthoclase crystal sections, one being parallel (Erebus-cryparallel) and the other orthogonal (Erebus-cry-perpendicular) to the main c axis (Fig. 4). Note that the composition of the crystal is slightly different ( $\mathrm{Fe}$-poorer and $\mathrm{CaO}$ richer) compared to the Erebus glass (Table 1). Moreover, the presence of small Fe-Ti oxide inclusions inside the crystals [35], [58], [59].

The evolution of the emissivity of these crystal sections measured during heating is presented in Fig. 4. In comparison with Fig. $2 b$ and $2 d$, the emissivity spectra of Erebus glass differ significantly from their crystalline counterparts. The differences are more marked at the lowest measured temperature, i.e., $\approx 800 \mathrm{~K}$. At low frequencies, the presence of four sharp spectral bands $\approx 535 \mathrm{~cm}^{-1}, 595 \mathrm{~cm}^{-1}, 1000 \mathrm{~cm}^{-1}$, and $1110 \mathrm{~cm}^{-1}$ are detected in both perpendicular and parallel crystal sections. They are clear witnesses of the long-range ordered crystal structure. It is clear that the exact positions, full widths at half maximum and especially intensities of these modes are strongly dependent on orientation. For example, the band at $1100 \mathrm{~cm}^{-1}$ appears as a shoulder in the case of parallel orientation whereas in the case of perpendicular section it is a rather well resolved sharp mode. Such differences confirm the anisotropic character of the anorthoclase crystal and reveal its impact on the spectral emissivity. Depending on the crystal orientation, spectral emissivity at a given temperature can vary by approximately 0.1 depending on wavenumber. Since the arrangement of the atoms is different following the crystallographic directions, the vibrational dynamics also differ, and thus the radiative properties. This structural arrangement explains also the important differences of spectral emissivity response between crystals and glasses.
At high wavenumbers, the emissivity of parallel and perpendicularly oriented crystals is rather similar to glass at 800 $\mathrm{K}$ having, however, a lower value (0.4 approximately) compared with its glassy counterpart $(\approx 0.6)$.

As temperature increases, the observed differences are mostly related to structural modifications occurring during melting (Fig. 4). At low wavenumbers, the vibrational modes broaden, consistent with thermal rise effects. Such broadening together with the mode merging increases more significantly near $1200 \mathrm{~K}$, and finally at the highest temperatures, the emissivity spectra reveal a molten glass structure. As shown in Fig. 4 (c-d), emissivity peaks at liquidus conditions. The temperature evolution of emissivity for both crystal sections is similar to glass, the main changes between these phases consisting in the progressive disappearance of the four spectral bands. However, strongly wavenumber-dependent differences are detected for the perpendicularly oriented section. The contrasted emissivity evolution of crystals as a function of temperature and wavenumber compared to the glassy materials underlines the potential impact of their presence on the bulk spectral emissivity of a real lava surface.

At high wavenumbers, emissivity increases significantly with temperature until around $1200 \mathrm{~K}$. Higher $(\approx 0.1$, for $\varepsilon$ between 3000-8000 $\mathrm{cm}^{-1}$ ) and more wavenumber dependent values are observed for the parallel cut. However, it should be noted that a small jump in emissivity appears in both crystals: between $830-1025 \mathrm{~K}$ for parallel (Fig. 4a) and $790-1105 \mathrm{~K}$ in the case of perpendicular cut (Fig. 4b). This jump in emissivity is similar to that observed for the Erebus glassy sample, but since its intensity is much lower, it does not give rise to opacification. The presence of $\mathrm{FeO}_{\mathrm{x}}$-based inclusions [58] heterogeneously distributed in the crystal could explain this phenomenon. Finally, at liquidus conditions, an emissivity drop $\left(\approx 0.2\right.$ at $\left.5000 \mathrm{~cm}^{-1}\right)$ is observed for both parallel and perpendicular sections. Considering that both crystals were fully melted at the highest temperatures, they consequently behave like a liquid (Fig. 2b and Fig. 4 c-d). Under these conditions the emissivity patterns of melted anorthoclases resemble that of Teide phonolite (Fig. 2a), consistent with the $\mathrm{Fe}$-poor character of these two materials.

Our results show clearly that the radiative properties of anorthoclase crystals are different from their glassy Erebus counterparts over the whole measured spectral range, despite their broadly similar bulk composition (Table 1). Accordingly, because magmas are generally crystal-bearing, with up to 50 wt $\%$ crystals erupted, e.g., [60], the impact of crystals on bulk emissivity has to be carefully considered.

\section{DISCUSSION}

\section{A. The T-E relationship-comparison of Teide and Erebus phonolites}

The in situ spectral emissivity results presented above clearly show how complex is the thermal evolution of the radiative properties of melt-rocks. In addition, the results show that the emissivity of Teide and Erebus exhibits different, particular evolution as a function of temperature and wavelength (Fig. 5), 
despite their chemical similarities. This is further illustrated in Fig. 5, where the T-E relationships for the two compositions are shown at two wavelengths, $9 \mu \mathrm{m}$ and $2.2 \mu \mathrm{m}$, which are pertinent to remote sensing, within the TIR and SWIR spectral regions, respectively.

The T-E relationship in the TIR (Fig. 5a-b) region shows clearly that the emissivity of both phonolites increases almost linearly with temperature, though with different slopes and intercepts for each composition, with a deviation from linearity being apparent in the temperature range $1300-1450 \mathrm{~K}$ for Erebus.

In contrast, the T-E relations at $2.2 \mu \mathrm{m}$ are not linear neither for Teide nor for Erebus, requiring higher order polynomials (2 for Teide and of 3 for Erebus). It should be stressed however that these mathematical functions are specific to $1.5 \mathrm{~mm}$ thick samples only. As shown in Fig. 2, at the $2.2 \mu \mathrm{m}$ both phonolites are semi-transparent: Teide over the entire measured temperature range and Erebus partially, i.e., except the opacification phenomenon detected between 950-1250 K. In the semi-transparent regime, the determined spectral emittance value is strongly thickness dependent. To illustrate the role of thickness, Fig. 6 shows the variation of spectral emissivity $(800 \mathrm{~K})$ as a function of sample thickness obtained with the use of Focus software [54], [55] which allows spectral modelling. The results reveal clearly that at $9 \mu \mathrm{m}$, where both samples are opaque, the emissivity values represent the semi-infinite behaviour, whereas at $2.2 \mu \mathrm{m}$ the recorded values depend strongly on the considered thicknesses. As presented in Fig. 7, in the case of Teide, the sample with a thickness of $20 \mathrm{~mm}$ can be representative of the semi-infinite behaviour. The case of Erebus is more complex, showing also the strong dependence of temperature: in the opacification domain, the sample reveals already semi-infinite regime whereas in the semi-transparent one the emissivity values depend on the thickness till $8 \mathrm{~mm}$.

\section{B. Comparison with previous studies}

To the best of our knowledge, only a handful of studies have investigated the radiative properties of lavas at high temperatures: Lombardo et al. [61] on Etna basalt up to 2300 $\mathrm{K}$, Lee et al. [8] on synthetic glasses up to $1673 \mathrm{~K}$, Rogic et al. [13] on Etna basalt up to $900 \mathrm{~K}$, Pisello et al. [10] on two series of alkaline et sub-alkaline synthetic glasses up to $873 \mathrm{~K}$ and Abtahi et al. [5] on Kīlauea basalt up to $1323 \mathrm{~K}$. The results of these works suggest that the emissivity of molten lava is significantly lower than that of its subsolidus and cooled counterpart, an observation at variance to ours.

Fig. 8 compares the emissivity spectra recorded by Lee $e t$ al. [8] and Rogic et al. [13] with our data for Erebus and Teide. As temperature increases, the emissivity of the synthetic glass used by Lee et al. [8] increases until $1473 \mathrm{~K}$ in perfect agreement with our observations. However, at $1573 \mathrm{~K}$, the results of Lee et al. [8] show an important emissivity decrease whereas values for Teide and Erebus both continue to increase with temperature. This is especially clear in the case of Teide sample, whose emissivity increases steadily with temperature until 2000 $\mathrm{K}$, as observed for pure silica $\mathrm{SiO}_{2}$ [43]. We note however, that the spectra recorded by Lee et al. [8] (Fig. 8a) at 1573 and 1673
$\mathrm{K}$ have "border" emissivity values exceeding 1 . This may reflect the use of internally heated furnaces along with powder samples in their experiments, which can lead to important temperature gradients and/or sample dimension changes, affecting in turn the emissivity response of the studied material. It has also been shown that the surface roughness, texture (e.g., ceramic or monocrystal), porosity, and particle size all affect emissivity [6], [7], [43], [47], and we infer that such contributing factors may have affected the high temperature data obtained by Lee et al. [8].

The data reported in Rogic et al. [13] (Fig. 8d) were acquired between 400 and $900 \mathrm{~K}$ but their emissivity spectra are presented in a raw state without the CF feature fixed to 1 (as in the case of our data or those of Lee et al. [8]), precluding investigation of the temperature relationship with emissivity [10].

In conclusion, the comparison of the temperature dependence of emissivity in the TIR region questions previous arguments that active lava always has lower emissivity than frozen lava. The data pertaining to the MIR and SWIR wavebands for Erebus at temperatures above $1300 \mathrm{~K}$ show that a continuous decrease of emissivity (from $\approx 0.98$ to 0.7 at $2.2 \mu \mathrm{m}$ ) occurs between 1185 and $1608 \mathrm{~K}$, yet it always remains higher than the emissivity of anorthoclase (about 0.6 , Fig. 4). Note that in the case of Teide sample, the highest emissivity values are recorded at the highest temperatures over the whole measured wavelength range.

\section{Role of cooling rate}

The effect of thermal history on the emissivity has been previously studied by Lee et al. [8] for two synthetic glasses with slightly different compositions, comparable to that of Erebus. Fig. 9 compares these datasets. In the TIR region, the emissivity of Erebus is not affected by the cooling rate whereas for the synthetic glasses faster cooling results in somewhat higher emissivity (Fig. 9a-b). However, the most important differences related to cooling rate for the Erebus sample are detected in the MIR-SWIR spectral regions, which were not explored in previous works. As shown in Fig. 9b, in the case of slow cooling, the sample approximates blackbody radiation whereas the initial emissivity state is recovered upon fast cooling. In the MIR and SWIR the emissivity variations related to differences in cooling rate can be as large as, or even more important than, those observed in the TIR.

\section{Role of crystals}

Few studies have measured crystal emissivity at magmatic temperatures [8], [11], [26]. Some studies have compared the emissivity spectra of oligoclase feldspar crystals quenched at different temperatures $(1373,1473,1773 \mathrm{~K})$ with those heated in a microfurnace at the same temperatures [8], [11]. In these works, the emissivity feature characteristic of the crystal structure is evident for the sample quenched at $1403 \mathrm{~K}$ but disappears above $1473 \mathrm{~K}$. This is broadly consistent with our observations of Erebus anorthoclase crystals that show clearly the disappearance of long-range crystal structure around 1500 K (Fig. 4). As shown in the IR study of forsterite [26], as 
temperature increases, the lattice anharmonicity and cation mobility increase significantly leading to anomalies in thermal radiative properties.

Fig. 10 superimposes the spectral emissivities of Erebus glass and anorthoclase crystal. Below $2000 \mathrm{~cm}^{-1}$ both materials share broadly the same spectra, but at higher wavenumbers, the emissivity of anorthoclase is significantly lower than that of the melt. It is thus clear that a high content of anorthoclase crystals should significantly change the thermodynamic surface temperature of Erebus phonolite lava, especially for measurements made at wavelengths lower than $5 \mu \mathrm{m}$. This point is further considered in the next section.

\section{E. Assessing the impact of crystals on Erebus magma emissivity}

The Erebus phonolite contains $30 \mathrm{wt} \%$ of anorthoclase crystals and minor amounts $(<1 \%)$ of accessory phases (pyroxene, olivine, and Ti-magnetite). It has been experimentally demonstrated that the proportion of K-feldspar in melt increases with decreasing temperature, this phase dominating the mineral assemblage as the magma cools down, hence exerting a dominant role on the radiative properties of the phonolite [35]. In order to evaluate the impact of crystals on Erebus lava phonolite emissivity we will only consider the contributions of the anorthoclases and the glassy/melt phase [35]. In a such crystal-melt system, the magma emissivity can be approximated by the simple relationship:

$\varepsilon_{\text {magma }}=\varepsilon_{\text {crystal }} \times \%_{\text {crystal }}+\varepsilon_{\text {matrix }} \times \%_{\text {matrix }}$

where \%crystal is the surface fraction of the crystal, \%matrix is the surface fraction of the matrix, $\varepsilon_{\text {crystal }}$ is the emissivity of the crystal and $\varepsilon_{\text {matrix }}$ is the emissivity of the glass matrix. As discussed in the previous section, this relationship is only correct for the TIR region $(>5 \mu \mathrm{m})$ where both glass and crystal counterparts are opaque.

Using (4), for a phonolite containing $30 \mathrm{wt} \% \mathrm{~K}$-feldspar and $70 \mathrm{wt} \%$ glassy matrix, the bulk emissivity is $7-11 \%$ lower than the values considered in previous works (Fig. $11 ; \varepsilon=1$ and 0.96 , [29], [31]).

The evolution of bulk $\varepsilon$ with crystal content calculated at 9 $\mu \mathrm{m}$ is presented in Fig. 11. At $9 \mu \mathrm{m}$, the change of $\varepsilon$ with crystallinity is modest, with a total $\varepsilon$ variation of 0.08 when the crystal content varies from 0 to $100 \%$ at a given temperature.

Note that, in the SWIR region, the direct determination of the crystal impact on radiative properties is not possible. The presence of anorthoclase crystals will increase consequently the transparency of the system giving rise to the modification of the radiative properties. The case of Erebus containing large size anorthoclase is exceptional, suggesting that semi-infinite behaviour with high emissivity values can be considered. However, one should be very careful when dealing with magma containing high content of small crystals (usually not exceeding $10 \mathrm{~mm}$ ) since they can significantly change then the radiative properties of lava flows. As shown in [26] the fosterite crystals are fully transparent above $3000 \mathrm{~cm}^{-1}(3.3 \mu \mathrm{m})$. In this case, the radiative measurements do not allow to determine the surface temperature and only give access to an average temperature of the participating volume.
From a general point of view, the bulk emissivity of a phonolitic magma ( $T>950 \mathrm{~K}$ ) decreases in the TIR region when the crystal content increases (assuming the volume fraction is equal to their surface fraction) if the temperature of the system is held constant (Fig. 11). This behaviour may have significant implications for interpreting the lava lake dynamics of Erebus volcano as inferred from IR imaging. The average crystal content of the Erebus phonolite in the lake has been estimated to be constant at $30 \mathrm{wt} \%$. However, if this mineral cargo is locally concentrated or diluted owing to fluid dynamics of the convecting lake [62], while maintaining temperature constant, this may lead to spurious interpretations. Associated $\varepsilon$ variations may be erroneously interpreted as due to the arrival of a new hot, crystal-poor, batch (high $\varepsilon$ ) or to crystal-rich and cold magma (low $\varepsilon$ ), compared to the average surrounding magma (Fig. 11).

The calculated relationship between crystal content and emissivity of Fig. 11 of Fe-rich phonolitic magmas contrasts with the observations of [8], [13], that report higher emissivity in the case of crystal-rich basaltic samples compared to their molten counterparts (down to 0.6 in this case). Leaving apart the contributions related to the measuring apparatus, experimental conditions and/or texture of the samples (granular powder vs glassy), this difference in radiative behaviour can be partially explained by higher proportions (up to $20 \mathrm{wt} \%$ ) [63] of Fe-Mg minerals (olivine, pyroxenes, Fe-Ti oxides) in basalts compared to Fe- and $\mathrm{Mg}$-poor phonolitic magmas [35], [40]. Iron-magnesium-rich mineral phases are indeed characterized by higher average $\varepsilon$ compared to K-feldspars, at least in the TIR region [26]; hence, the presence of large amounts of $\mathrm{Fe}-\mathrm{Mg}$ crystals in the basaltic magma may positively impact the bulk $\varepsilon$ according to (4), even if different amounts of plagioclase cocrystallize. To a first approximation, the effect of crystallinity on bulk $\varepsilon$ calculated here for Erebus can be anticipated to be similar for evolved compositions like rhyodacites-rhyolites, because the mineralogy is also dominated by plagioclase and or k-feldspar [64].

\section{F. Erebus lava lake temperature}

The first field measurements of the lava lake temperature were performed by Kyle et al. [65] with an optical pyrometer giving an estimate of $1273 \pm 20 \mathrm{~K}$, though no information was provided on emissivity values used to determine temperature. Satellite remote sensing estimates have also been reported by Rothery and Francis [66], using Landsat Thematic Mapper (TM) images, yielding estimates between 1173 and $1403 \mathrm{~K}$. These measurements were performed with an image resolution of $30 \mathrm{~m}$ on bands $5(1.55-1.75 \mu \mathrm{m})$ and $7(2.08-2.35 \mu \mathrm{m})$ assuming an emissivity for phonolite of 0.6 [32]. More recently, Calkins et al. [31] using an infrared camera working in the 3.6$5.0 \mu \mathrm{m}$ spectral range and assuming an in-band emissivity of unity, inferred temperatures of 546-1173 K and 546-1196 K for the permanent Ray and ephemeral Werner lava lakes, respectively.

Davies et al. [29] combined measurements from two infrared cameras (FLIR ThermaCAM P65 and EX320) taking in-band emissivity of 0.96 and over the 7.5-13 $\mu \mathrm{m}$ range (combining 
ASTER, Hyperion, MODIS, and ALI on board devices covering SWIR-TIR regions). Retrieved temperatures range between $575 \mathrm{~K}$ and $1090 \mathrm{~K}$, with a mode around 730-850 K, thus lying at the lower end of previous estimates. Interestingly, the ASTER surface emissivity data derived using TES from the TIR region $(8-11 \mu \mathrm{m})$ varied between 1 and 0.54 (at $11 \mu \mathrm{m}$ ). Our measurements however do not show $\varepsilon$ values as low as 0.54 in the TIR region: it should be stressed again that our measurements are made on samples with a thickness of $1.5 \mathrm{~mm}$, hence they can be used directly for the TIR region, but are however not applicable in any straightforward manner for the SWIR region.

The in-situ emissivity data presented in this work allow us to refine these previous estimates over a large spectral range (Table 2). These already include the bulk background Eradiance, atmospheric absorptions and roughness corrections considered in previous works, since addressing the contributions of these parameters to the final $\mathrm{T}$ was out of scope. The assumed in-band emissivity values of 1 or 0.96 used in previous works [29], [31] were then replaced by the experimentally measured spectral emissivity values which already accounts for the $30 \mathrm{wt} \%$ anorthoclase in the magma. Maximum surface temperature of Ray lake ranges from $1174 \mathrm{~K}$ to $1210 \mathrm{~K}$ whereas the surface temperature retrieved by EO-1 Hyperion ranges from $995 \mathrm{~K}$ to $1017 \mathrm{~K}$.

It is thus clear that the choice of appropriated emissivity values for a given wavelength has important consequences on retrieved temperature. This is highlighted in Fig. 12, which shows that a decrease of $\varepsilon$ from 1 to 0.8 introduces a $\Delta \mathrm{T}$ of 157 $\mathrm{K}$ for the Erebus magma at $9 \mu \mathrm{m}$ TIR wavelength. In this case, TIR appears to be more sensible to emissivity modifications and can propagate significant errors to the final determined $\mathrm{T}$.

\section{CONCLUSION}

The goal of the present study was to determine the radiative properties of two representative phonolitic magmatic rocks from Erebus and Teide volcanoes. To achieve this, in situ measurements of emissivity at high temperatures - up to liquid lava state, were performed across a very wide spectral range spanning thermal-, mid-, and shortwave-infrared regions. Our results show clearly that spectral emissivity is a complex function of temperature, composition, structure and thermal history. The comparison of observations for phonolite samples from Erebus and Teide reveals that the temperature dependencies of spectral emissivity are different for these two phonolites, despite their similar compositions. In the case of Teide sample, the highest emissivity values are recorded at the highest temperatures over the whole measured wavelength range. In contrast, the behavior of Erebus appears more complex presenting in particular the opacification phenomenon in the 950-1250 K temperature range. These results demonstrate that the use of a constant emissivity value for a given rock family may not be good proxy for a particular composition. Our results show also that active lava may not have a lower emissivity than that of solid counterparts (i.e., crust), depending on the relative proportions of $\mathrm{Fe}$ bearing and Fe-free silicates. The presence of crystals in magma can additionally modify this already complex emissivity behavior. The crystal type, size and thickness can significantly change the radiative properties of the lava, both in TIR and SWIR.

The Erebus sample displays a particular behavior in relation to the thermal history of the magma: each cooling rate matches a value of emissivity. According to our data, the emissivity of the lava flow is higher than that of the bomb at the same thickness, hence their thermal propriety should be considered as different. This information is also useful for lava flow models: the more the temperature is underestimated, the more the hazard impact zone will also be underestimated. Further, our emissivity results allow us not only to improve temperature measurements but also to reconstruct the thermal history of the sample collected in the field. Our results also highlight that the TES method (or other algorithms) used to retrieve the temperature and emissivity for magmas (or other hot bodies) should be used with caution, because, at present, the method is calibrated from measurements made at low temperature, and the information about emissivity at high temperature is generally missing.

Finally, we point out that our work represents the first step towards a more systematic and detailed knowledge of magma radiative properties. Current efforts of our team focus on the emissivity behavior of basalt-like composition, which are the most abundant magmas on planets, and for which a detailed understanding of radiative properties is required.

\section{ACKNOWLEDGMENT}

Lionel Cosson (CEMHTI) is acknowledge for his kind help with IR emissivity measurements. Ida di Carlo and Patricia Benoist (ISTO) are warmly thanked for their support during SEM and EMPA measurements.

\section{REFERENCES}

[1] K. D. Putirka, "Mantle potential temperatures at Hawaii, Iceland, and the mid-ocean ridge system, as inferred from olivine phenocrysts: Evidence for thermally driven mantle plumes," Geochem., Geophys., Geosyst., vol. 6, no. 5, 2005.

[2] T. C. Wilkes, L. R. Stanger, J. R. Willmott, T. D. Pering, A. J. S. McGonigle, R. A. England, "The Development of a Low-Cost, Near Infrared, High-Temperature Thermal Imaging System and Its Application to the Retrieval of Accurate Lava Lake Temperatures at Masaya Volcano, Nicaragua," Remote Sens., vol. 10, no. 3, p. 450, 2018.

[3] M. Aufaristama, A. Hoskuldsson, I. Jonsdottir, M. O. Ulfarsson, and T. Thordarson, "New Insights for Detecting and Deriving Thermal Properties of Lava Flow Using Infrared Satellite during 2014-2015 Effusive Eruption at Holuhraun, Iceland," Remote Sens., vol. 10, no. 1, p. 151, 2018

[4] J. O. Thompson and M. S. Ramsey, "Uncertainty Analysis of Remotely-Acquired Thermal Infrared Data to Extract the Thermal Properties of Active Lava Surfaces," Remote Sens., vol. 12, no. 1, p. 193, 2020.

[5] A. A. Abtahi, A. B. Kahle, E. A. Abbott, A. R. Gillespie, D. Sabol, G. Yamada, and D. Pieri, "Emissivity Changes in Basalt Cooling After Eruption From PU'U O'O, Kilauea, Hawaii," in AGU Fall Meeting Abstr., 2002, abstract no. F1442.

[6] J. M. Byrnes, M. S. Ramsey, P. L. King, and R. J. Lee, "Thermal infrared reflectance and emission spectroscopy of quartzofeldspathic glasses," Geophys. Res. Lett., vol. 34, no. $1,2007$. 
[7] A. Harris, Thermal remote sensing of active volcanoes: a user's manual. Cambridge, UK: Cambridge univ. press, 2013.

[8] R. J. Lee, M. S. Ramsey, and P. L. King, "Development of a new laboratory technique for high-temperature thermal emission spectroscopy of silicate melts," J. Geophys. Res.: Solid Earth, vol. 118, no. 5, pp. 1968-1983, 2013.

[9] H. Li, "Appproche structurale in situ des milieux fondus sous conditions extrêmes de température et de pression," Ph.D. dissertation, Université d'Orléans, Orléans, France, 2018.

[10] A. Pisello, F. P. Vetere, M. Bisolfati, A. Maturilli, D. Morgavi, C. Pauselli, G. Iezzi, M. Lustrino, and D. Perugini, "Retrieving magma composition from TIR spectra: implications for terrestrial planets investigations," Sci. Rep., vol. 9, no. 1, p. 15200, Oct. 23, 2019.

[11] M. S. Ramsey, "Quantitative analysis of geological surfaces: A deconvolution algorithm for midinfrared remote sensing data," Ph.D. dissertation, Ariz. State Univ., Tempe, AZ, USA, 1996.

[12] M. S. Ramsey, M. O. Chevrel, D. Coppola, and A. Harris, "The influence of emissivity on the thermo-rheological modeling of the channelized lava flows at Tolbachik volcano," Annals of Geophysics, vol. 62, no. 2, p. VO222, 2019.

[13] N. Rogic, A. Cappello, and F. Ferrucci, "Role of Emissivity in Lava Flow 'Distance-to-Run' Estimates from SatelliteBased Volcano Monitoring," Remote Sens., vol. 11, no. 6, p. 662, 2019.

[14] N. Rogic, A. Cappello, G. Ganci, A. Maturilli, H. Rymer, S. Blake, and F. Ferrucci, "Spaceborne EO and a Combination of Inverse and Forward Modelling for Monitoring Lava Flow Advance," Remote Sens., vol. 11, no. 24, p. 3032, 2019.

[15] M. S. Ramsey and P. R. Christensen, "Mineral abundance determination: Quantitative deconvolution of thermal emission spectra," J. Geophys. Res.: Solid Earth, vol. 103, no. B1, pp. 577-596, 1998.

[16] D. D. S. Meneses, M. Eckes, L. del Campo, C. N. Santos, Y. Vaills, and P. Echegut, "Investigation of medium range order in silicate glasses by infrared spectroscopy," Vib. Spectrosc., vol. 65, pp. 50-57, Mar. 2013.

[17] P. McMillan and B. Piriou, "The structures and vibrational spectra of crystals and glasses in the silica-alumina system," J. Non-Cryst. Solids, vol. 53, no. 3, pp. 279-298, Dec. 1982.

[18] B. O. Mysen, D. Virgo, and F. A. Seifert, "The structure of silicate melts: Implications for chemical and physical properties of natural magma," Rev. Geophys., vol. 20, no. 3, pp. 353-383, Aug. 1982.

[19] C. Oppenheimer, B. Scaillet, A. Woods, A. J. Sutton, T. Elias, and Y. Moussallam, "Influence of eruptive style on volcanic gas emission chemistry and temperature," Nat. Geosci., vol. 11, no. 9, pp. 678-681, Aug. 6, 2018.

[20] A. Gillespie, S. Rokugawa, T. Matsunaga, J. S. Cothern, S. Hook, and A. B. Kahle, "A temperature and emissivity separation algorithm for Advanced Spaceborne Thermal Emission and Reflection Radiometer (ASTER) images," IEEE Trans. Geosci. Remote Sens., vol. 36, no. 4, pp. 11131126, Jul. 1998.

[21] J. A. Sobrino, J. C. Jiménez-Muñoz, and L. Paolini, "Land surface temperature retrieval from LANDSAT TM 5," Remote Sens. Environ., vol. 90, no. 4, pp. 434-440, Apr. 30, 2004.

[22] Z. L. Li, B. H. Tang, H. Wu, H. Z. Ren, G. J. Yan, Z. M. Wan, I. F. Trigo and J. A. Sobrino, "Satellite-derived land surface temperature: Current status and perspectives," Remote Sens. of Environ., vol. 131, pp. 14-37, Apr. 15, 2013.

[23] M. Ball and H. Pinkerton, "Factors affecting the accuracy of thermal imaging cameras in volcanology," J. Geophys. Res.: Solid Earth, vol. 111, no. B11, Nov. 2006.

[24] H. Pinkerton, M. James, and A. Jones, "Surface temperature measurements of active lava flows on Kilauea volcano, Hawai'i," J. Volcanol. Geotherm. Res., vol. 113, no. 1-2, pp. 159-176, Mar. 15, 2002.

[25] O. Rozenbaum, D. D. S. Meneses, and P. Echegut, "Texture and Porosity Effects on the Thermal Radiative Behavior of
Alumina Ceramics," Int. J. Thermophys., vol. 30, no. 2, pp. 580-590, Apr. 2009.

[26] M. Eckes, B. Gibert, D. D. S. Meneses, M. Malki, and P. Echegut, "High-temperature infrared properties of forsterite," Phys. Chem. Miner., vol. 40, no. 4, pp. 287-298, Apr. 2013.

[27] S. W. Ruff, P. R. Christensen, P. W. Barbera, and D. L. Anderson, "Quantitative thermal emission spectroscopy of minerals: A laboratory technique for measurement and calibration," J. Geophys. Res.: Solid Earth, vol. 102, no. B7, pp. 14899-14913, Jul. 10, 1997.

[28] J. O. Thompson, M. S. Ramsey, and J. L. Hall, "MMT-Cam: A New Miniature Multispectral Thermal Infrared Camera System for Capturing Dynamic Earth Processes," IEEE Trans. Geosci. Remote Sens., vol. 57, no. 10, pp. 7438-7446, Oct. 2019.

[29] A. G. Davies, J. Calkins, L. Scharenbbroich, R. G. Vaughan, R. Wright, P. Kyle, R. Castano, S. Chien, D. Tran, "Multiinstrument remote and in situ observations of the Erebus Volcano (Antarctica) lava lake in 2005: A comparison with the Pele lava lake on the jovian moon Io," J. Volcanol. Geotherm. Res., vol. 177, no. 3, pp. 705-724, Nov. 10, 2008.

[30] A. Harris, R. Wright, and L. P. Flynn, "Remote monitoring of Mount Erebus Volcano, Antarctica, using Polar Orbiters: Progress and Prospects," Int. J. Remote Sens., vol. 20, no. 1516, pp. 3051-3071, 1999.

[31] J. Calkins, C. Oppenheimer, and P. R. Kyle, "Ground-based thermal imaging of lava lakes at Erebus volcano, Antarctica," J. Volcanol. Geotherm. Res., vol. 177, no. 3, pp. 695-704, Nov. 10, 2008.

[32] D. A. Rothery, P. W. Francis, and C. A. Wood, "Volcano monitoring using short wavelength infrared data from satellites," J. Geophys. Res.: Solid Earth, vol. 93, no. B7, pp. 7993-8008, Jul. 10, 1988.

[33] A. Burgisser, C. Oppenheimer, M. Alletti, P. R. Kyle, B. Scaillet, and M. R. Carroll, "Backward tracking of gas chemistry measurements at Erebus volcano," Geochem., Geophys., Geosyst., vol. 13, no. 11, Nov. 2012.

[34] C. Le Losq, D. R. Neuville, R. Moretti, P. R. Kyle, and C. Oppenheimer, "Rheology of phonolitic magmas - the case of the Erebus lava lake," Earth Planet. Sci. Lett., vol. 411, pp. 53-61, Feb. 1, 2015.

[35] Y. Moussallam, C. Oppenheimer, B. Scaillet, and P. R. Kyle, "Experimental Phase-equilibrium Constraints on the Phonolite Magmatic System of Erebus Volcano, Antarctica," J. Petrol., vol. 54, no. 7, pp. 1285-1307, Jul. 2013.

[36] B. Hirn, C. D. Bartola, and F. Ferrucci, "Spaceborne Monitoring 2000-2005 of the Pu'u 'O'o-Kupaianaha (Hawaii) Eruption by Synergetic Merge of Multispectral Payloads ASTER and MODIS," IEEE Trans. Geosci. Remote Sens., vol. 46, no. 10, pp. 2848-2856, Oct. 2008.

[37] G. C. Hulley, S. J. Hook, E. Abbott, N. Malakar, T. Islam, and M. Abrams, "The ASTER Global Emissivity Dataset (ASTER GED): Mapping Earth's emissivity at 100 meter spatial scale," Geophys. Res. Lett., vol. 42, no. 19, pp. 79667976, Oct. 16, 2015.

[38] S. R. Rose, I. M. Watson, M. S. Ramsey, and C. G. Hughes, "Thermal deconvolution: Accurate retrieval of multispectral infrared emissivity from thermally-mixed volcanic surfaces," Remote Sens. Environ., vol. 140, pp. 690-703, Jan. 2014.

[39] J. Andújar and B. Scaillet, "Relationships between preeruptive conditions and eruptive styles of phonolite-trachyte magmas," Lithos, vol. 152, pp. 122-131, Nov. 1, 2012.

[40] J. Andújar, F. Costa, and B. Scaillet, "Storage conditions and eruptive dynamics of central versus flank eruptions in volcanic islands: The case of Tenerife (Canary Islands, Spain)," J. Volcanol. Geotherm. Res., vol. 260, pp. 62-79, Jun. 15, 2013.

[41] D. D. S. Meneses, M. Malki, and P. Echegut, "Optical and structural properties of calcium silicate glasses," J. NonCryst. Solids, vol. 352, no. 50-51, pp. 5301-5308, Dec. 1, 2006.

[42] J. F. Brun, "Mesure et analyse de l'émittance spectrale d'oxydes diélectriques à haute température : une approche 
des phénomènes préfusionnels," Ph.D. dissertation, Université d'Orléans, Orléans, France, 2003.

[43] O. Rozenbaum, D. D. S. Meneses, Y. Auger, S. Chermanne, and P. Echegut, "A spectroscopic method to measure the spectral emissivity of semi-transparent materials up to high temperature," Rev. Sci. Instrum., vol. 70, no. 10, pp. 40204025, 1999.

[44] D. D. S. Meneses, P. Melin, L. del Campo, L. Cosson, and P. Echegut, "Apparatus for measuring the emittance of materials from far infrared to visible wavelengths in extreme conditions of temperature," Infrared Phys. Technol., vol. 69, pp. 96-101, Mar. 2015.

[45] M. Eckes, "Opacification of dielectric oxides near the melting point," Ph.D. dissertation, Université d'Orléans, Orléans, France, 2012.

[46] B. Rousseau, J. F. Brun, D. D. S. Meneses, and P. Echegut, "Temperature Measurement: Christiansen Wavelength and Blackbody Reference," Int. J. Thermophys., vol. 26, no. 4, pp. 1277-1286, Jul. 2005.

[47] A. Maturilli, J. Helbert, A. Witzke, and L. Moroz, "Emissivity measurements of analogue materials for the interpretation of data from PFS on Mars Express and MERTIS on Bepi-Colombo," Planet. Space Sci., vol. 54, no. 11, pp. 1057-1064, Sep. 2006.

[48] L. P. Flynn and P. J. Mouginis-Mark, "Cooling rate of an active Hawaiian lava flow from nighttime spectroradiometer measurements," Geophys. Res. Lett., vol. 19, no. 17, pp. 1783-1786, Sep. 4, 1992.

[49] J. Gottsmann and D. B. Dingwell, "Cooling dynamics of spatter-fed phonolite obsidian flows on Tenerife, Canary Islands," J. Volcanol. Geotherm. Res., vol. 105, no. 4, pp. 323-342, Mar. 2001.

[50] A. Harris, J. Bailey, S. Calvari, and J. Dehn, "Heat loss measured at a lava channel and its implications for downchannel cooling and rheology," Geol. Soc. Am., vol. 396, pp. 125,2005

[51] K. Hon, J. Kauahikaua, R. Denlinger, and K. Mackay, "Emplacement and inflation of pahoehoe sheet flows: Observations and measurements of active lava flows on Kilauea Volcano, Hawaii," Geol. Soc. Am. Bull., vol. 106, no. 3, pp. 351-370, Mar. 1, 1994.

[52] M. Wilding, D. Dingwell, R. Batiza, and L. Wilson, "Cooling rates of hyaloclastites: applications of relaxation geospeedometry to undersea volcanic deposits," Bull. Volcanol., vol. 61, no. 8, pp. 527-536, Feb. 2000.

[53] M. Wilding, S. Webb, D. Dingwell, G. Ablay, and J. Marti, "Cooling rate variation in natural volcanic glasses from Tenerife, Canary Islands," Contrib. Mineral. Petrol., vol. 125, no. 2, pp. 151-160, Oct. 1996.

[54] D. D. S. Meneses, M. Malki, and P. Echegut, "Structure and lattice dynamics of binary lead silicate glasses investigated by infrared spectroscopy," J. Non-Cryst. Solids, vol. 352, no. 8, pp. 769-776, Jun. 1, 2006.
[55] D. D. S. Meneses, J. F. Brun, P. Echegut, and P. Simon, "Contribution of Semi-Quantum Dielectric Function Models to the Analysis of Infrared Spectra," Appl. Spectrosc., vol. 58, no. 8, pp. 969-974, 2004.

[56] P. A. Bingham, J. M. Parker, T. Searle, J. M. Williams, and I. Smith, "Novel structural behaviour of iron in alkalialkaline-earth-silica glasses," C. R. Chim., vol. 5, no. 11, pp. 787-796, Nov. 2002.

[57] R. J. Lee, P. L. King, and M. S. Ramsey, "Spectral analysis of synthetic quartzofeldspathic glasses using laboratory thermal infrared spectroscopy," J. Geophys. Res.: Solid Earth, vol. 115, no. B6, Jun. 2010.

[58] P. R. Kyle, "Mineralogy and glass chemistry of recent volcanic ejecta from Mt Erebus, Ross Island, Antarctica," New Zealand J. Geol. Geophys., vol. 20, no. 6, pp. 11231146, 1977.

[59] Y. Moussallam, C. Oppenheimer, B. Scaillet, I. Buisman, C. Kimball, N. Dunbar, A. Burgisser, C. I. Schipper, J. Andujar, P. Kyle, "Megacrystals track magma convection between reservoir and surface," Earth Planet. Sci. Lett., vol. 413, pp. 1-12, Mar. 01, 2015.

[60] B. Scaillet, F. Holtz, and M. Pichavant, "Phase equilibrium constraints on the viscosity of silicic magmas: 1 . Volcanicplutonic comparison," J. Geophys. Res.: Solid Earth, vol. 103, no. B11, pp. 27257-27266, Nov. 10, 1998.

[61] V. Lombardo, L. Pick, C. Spinetti, J. Tadeucci, K. Zakšek, "Temperature and Emissivity Separation 'Draping' Algorithm Applied to Hyperspectral Infrared Data," Remote Sens., vol. 12, no. B12, p. 2046, 2020.

[62] C. Oppenheimer, R. Moretti, P. R. Kyle, A. Eschenbacher, J. B. Lowenstern, R. L. Hervig, and N. W. Dunbar, "Mantle to surface degassing of alkalic magmas at Erebus volcano, Antarctica," Earth Planet. Sci. Lett., vol. 306, no. 3, pp. 261 271, Jun. 15, 2011.

[63] J. Andújar, B. Scaillet, M. Pichavant, and T. H. Druitt, "Differentiation Conditions of a Basaltic Magma from Santorini, and its Bearing on the Production of Andesite in Arc Settings," J. Petrol., vol. 56, no. 4, pp. 765-794, Apr. 2015.

[64] B. Scaillet, F. Holtz, and M. Pichavant, "Experimental Constraints on the Formation of Silicic Magmas," Elements, vol. 12, no. 2, pp. 109-114, Apl. 2016.

[65] P. R. Kyle, R. R. Dibble, W. F. Giggenbach, and J. Keys, "Volcanic activity associated with the anorthoclase phonolite lava lake, Mount Erebus, Antarctica," Antarctic Geosci., Madison, WI, USA: Univ. Wisconsin Press, pp. 735-745, 1982.

[66] D. A. Rothery and P. W. Francis, "Cover Short wavelength infrared images for volcano monitoring," Int. J. Remote Sens., vol. 11, no. 10, pp. 1665-1667, 1990. 
List of Figure Captions:

Fig. abstract. Temperature evolution of spectral emissivity of the Erebus sample (thickness: $1.5 \mathrm{~mm}$ ) with superimposed typical bands covered by ASTER satellite.

Fig. 1. In-situ apparatus for direct emissivity measurements a) general view and b) spectra acquisition scheme (after [44]).

Fig. 2. Temperature evolution of spectral emissivity characteristics of Teide (a, c) and Erebus samples (b, d): a and $\mathrm{b}$ : the whole measured spectral range; $\mathrm{c}$ and $\mathrm{d}$ : focus on lower frequencies spanning the TIR. Note that the spectra recorded at $\approx 760 \mathrm{~K}$ could be recorded only up to $6000 \mathrm{~cm}^{-1}$ beyond which there is insufficient radiation reaching the detector. Note: All emissivity's measurements here and below in this work were made with samples' thickness of $1.5 \mathrm{~mm}$.

Fig. 3. Comparison of spectral emissivity of Erebus sample (thickness: $1.5 \mathrm{~mm}$ ) recorded at $750 \mathrm{~K}$ before further heating and after different rates of cooling $(\mathrm{a}, \mathrm{c})$ : fast (quenched bomb) or slow (lava flow); Temperature evolution of spectral emissivity of Erebus sample recorded during the slow cooling (b,d).

Fig. 4. Changing spectral emissivity at different temperatures for Erebus anorthoclase crystal (thickness: 1.5 $\mathrm{mm})$ sections parallel $(\mathrm{a}, \mathrm{c})$ and perpendicular $(\mathrm{b}, \mathrm{d})$ to main $\mathrm{c}$ axis.
Fig. 5. The Temperature-Emissivity relationships of Teide and Erebus samples at $9 \mu \mathrm{m}(\mathrm{a}, \mathrm{b})$ and $2.2 \mu \mathrm{m}(\mathrm{c}, \mathrm{d})$. Note: The values used correspond to the emissivity of a $1.5 \mathrm{~mm}$ thick samples with polished surface (normal incidence).

Fig. 6. Thickness dependence of emissivity for Teide and Erebus samples, simulated with the Focus software [54], [55].

Fig. 7. Evolution of spectral emissivity at $2.2 \mu \mathrm{m}$ as a function of thickness at two different temperatures for Teide and Erebus samples.

Fig. 8. Comparison of temperature dependences of spectral emissivity reported in previous works $(a, d)$ [8], [13], and in this study (b, c).

Fig. 9. Comparison of spectral emissivity recorded after slow or fast cooling (quench) in previous work (panels a,c) [8], and in this study (b).

Fig. 10. Comparison of spectral emissivity between anorthoclase crystal and Erebus glass samples around $1200 \mathrm{~K}$ (a, c) and $1500 \mathrm{~K}(\mathrm{~b}, \mathrm{~d})$.

Fig. 11. The impact of crystal content on the total magma Erebus emissivity as a function of temperature, calculated for the wavelength at $9 \mu \mathrm{m}$.

Fig. 12. Impact of change in emissivity (from 1 to 0.8 ) on retrieved temperature in the $9 \mu \mathrm{m}$ TIR region for the Erebus phonolite. 


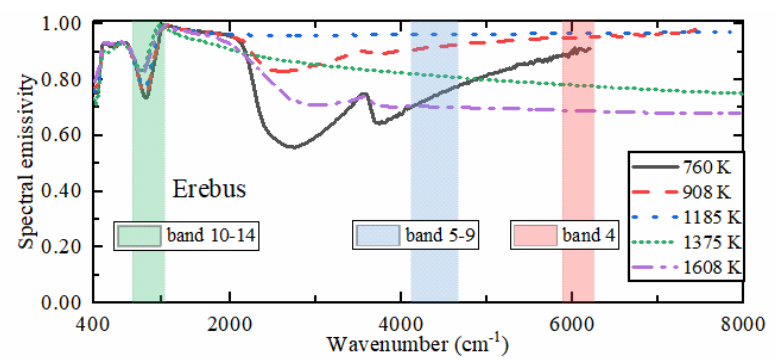

Fig. abstract. Temperature evolution of spectral emissivity of the Erebus sample (thickness: 1.5 mm) with superimposed typical bands covered by ASTER satellite. 

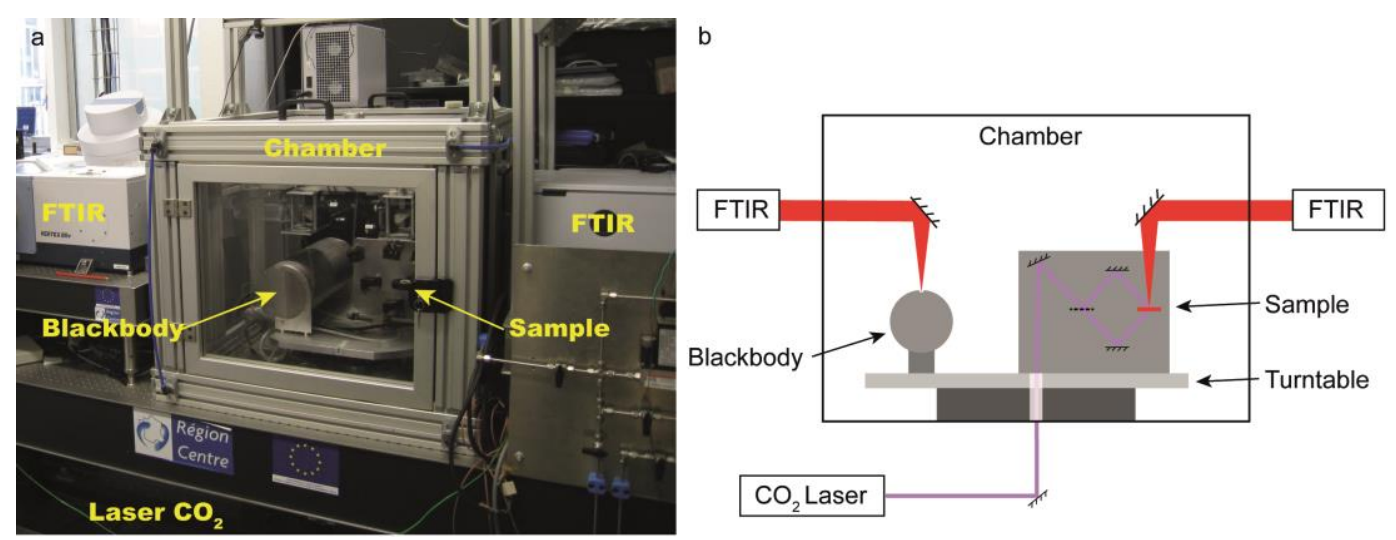

Fig. 1. In-situ apparatus for direct emissivity measurements a) general view and b) spectra acquisition scheme (after [44]). 


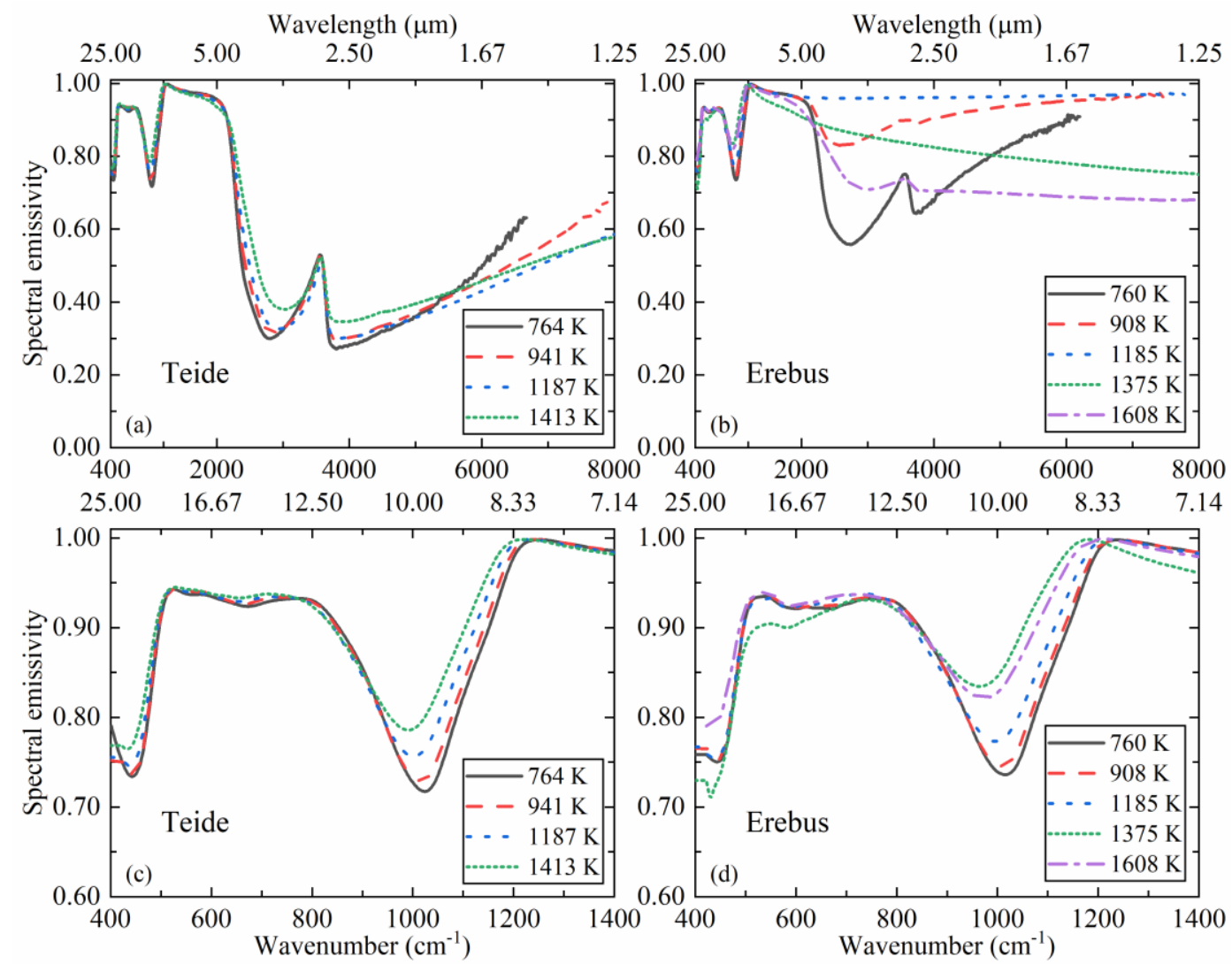

Fig. 2. Temperature evolution of spectral emissivity characteristics of Teide (a, c) and Erebus samples (b, d): a and b: the whole measured spectral range; $\mathrm{c}$ and $\mathrm{d}$ : focus on lower frequencies spanning the TIR. Note that the spectra recorded at $\approx 760 \mathrm{~K}$ could be recorded only up to $6000 \mathrm{~cm}^{-1}$ beyond which there is insufficient radiation reaching the detector. Note: All emissivity's measurements here and below in this work were made with samples' thickness of $1.5 \mathrm{~mm}$. 

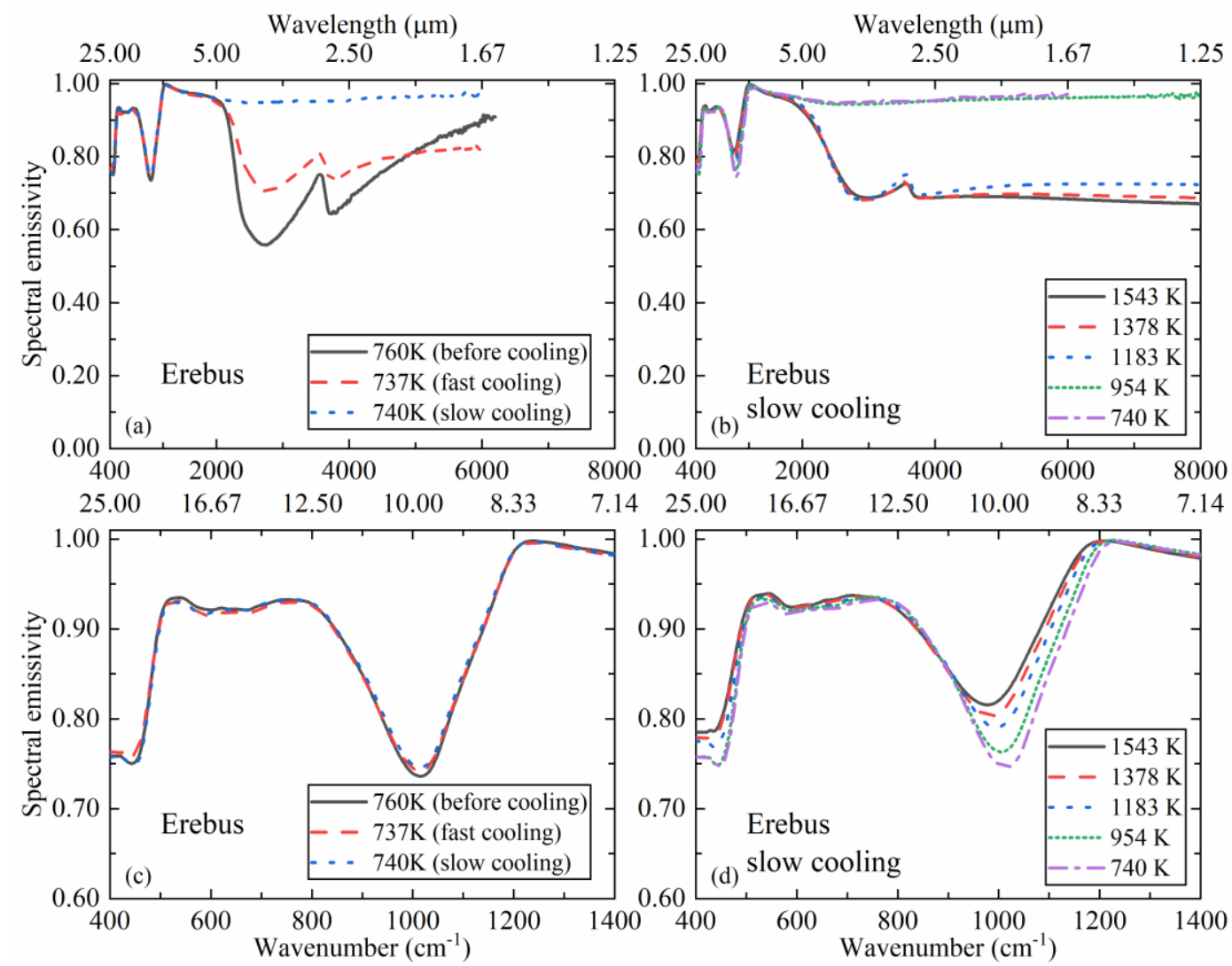

Fig. 3. Comparison of spectral emissivity of Erebus sample (thickness: $1.5 \mathrm{~mm}$ ) recorded at $750 \mathrm{~K}$ before further heating and after different rates of cooling (a,c): fast (quenched bomb) or slow (lava flow); Temperature evolution of spectral emissivity of Erebus sample recorded during the slow cooling $(b, d)$. 

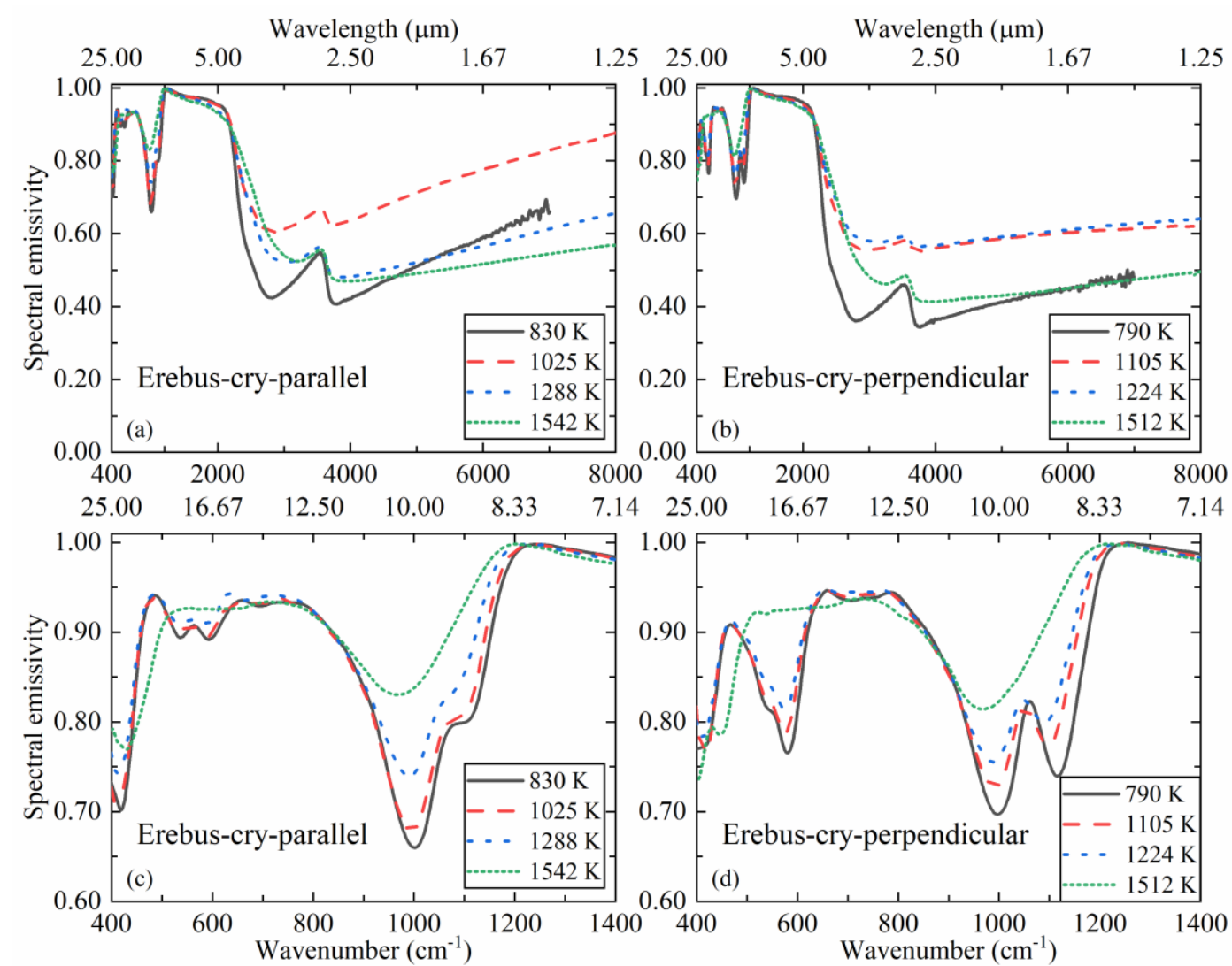

Fig. 4. Changing spectral emissivity at different temperatures for Erebus anorthoclase crystal (thickness: $1.5 \mathrm{~mm})$ sections parallel $(a, c)$ and perpendicular $(b, d)$ to main $c$ axis. 

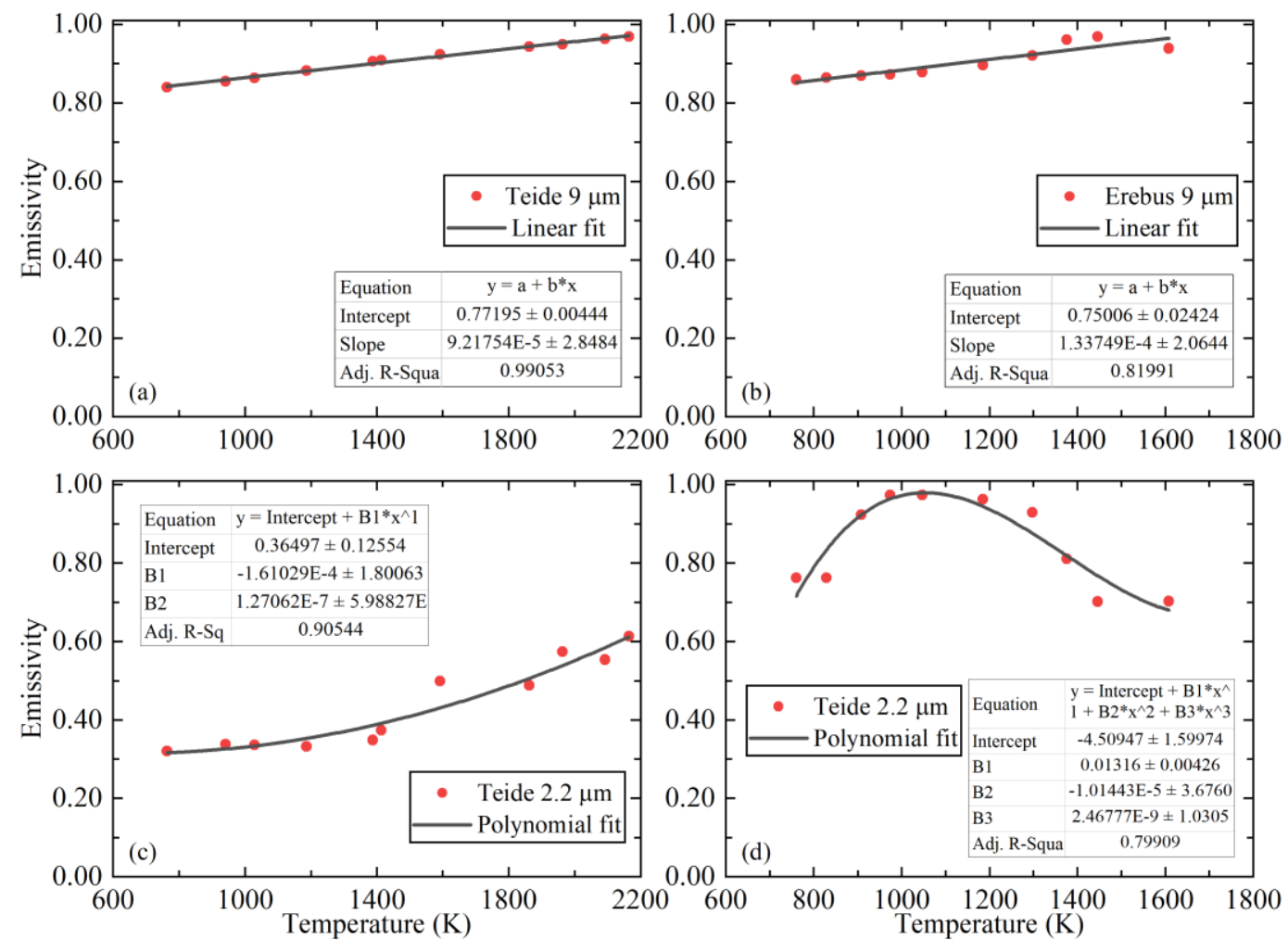

Fig. 5. The Temperature-Emissivity relationships of Teide and Erebus samples at $9 \mu \mathrm{m}(\mathrm{a}, \mathrm{b})$ and $2.2 \mu \mathrm{m}(\mathrm{c}, \mathrm{d})$. Note: The values used correspond to the emissivity of a $1.5 \mathrm{~mm}$ thick samples with polished surface (normal incidence). 


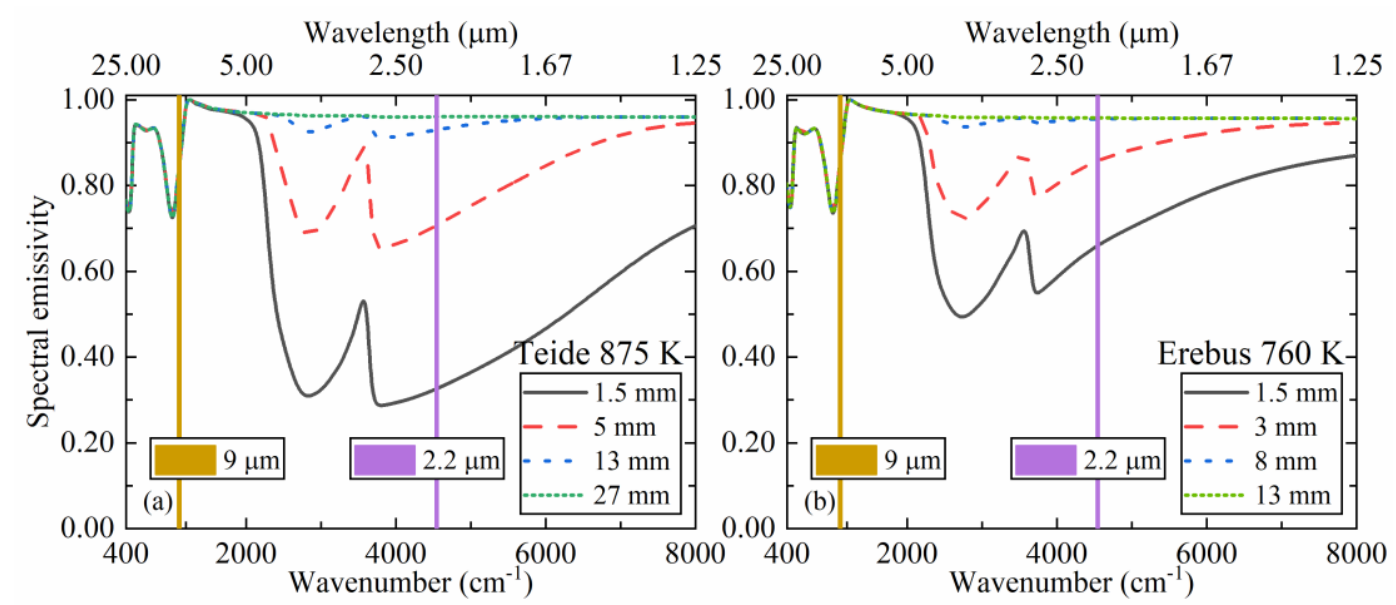

Fig. 6. Thickness dependence of emissivity for Teide and Erebus samples, simulated with the Focus software [54], [55]. 

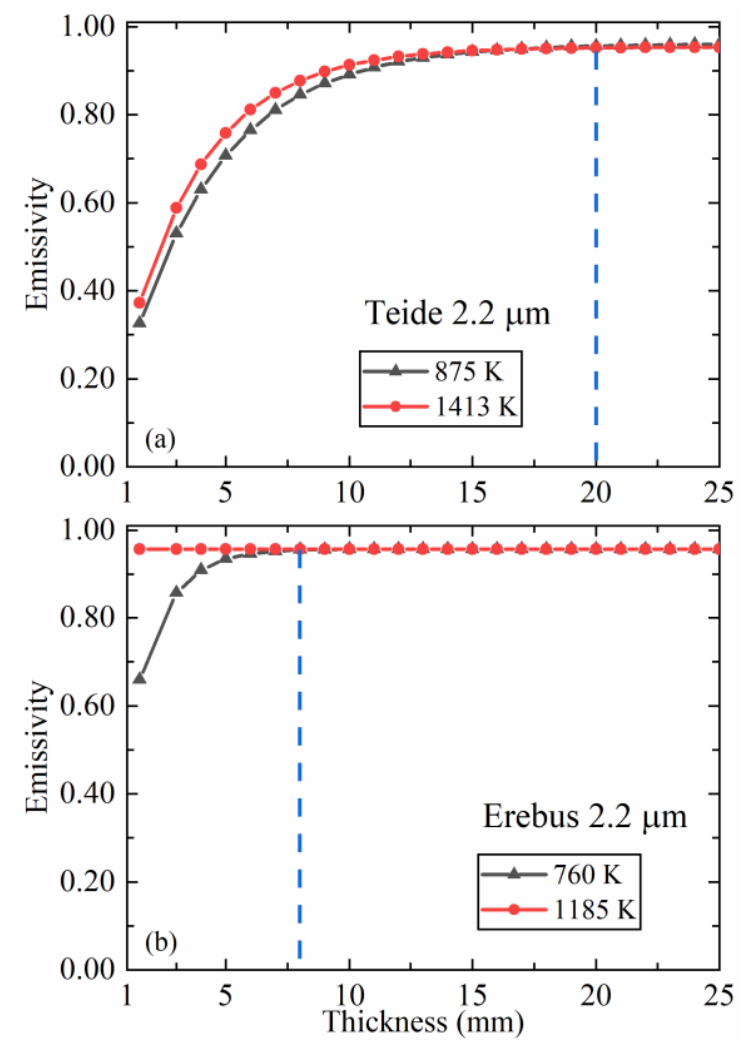

Fig. 7. Evolution of spectral emissivity at $2.2 \mu \mathrm{m}$ as a function of thickness at two different temperatures for Teide and Erebus samples. 

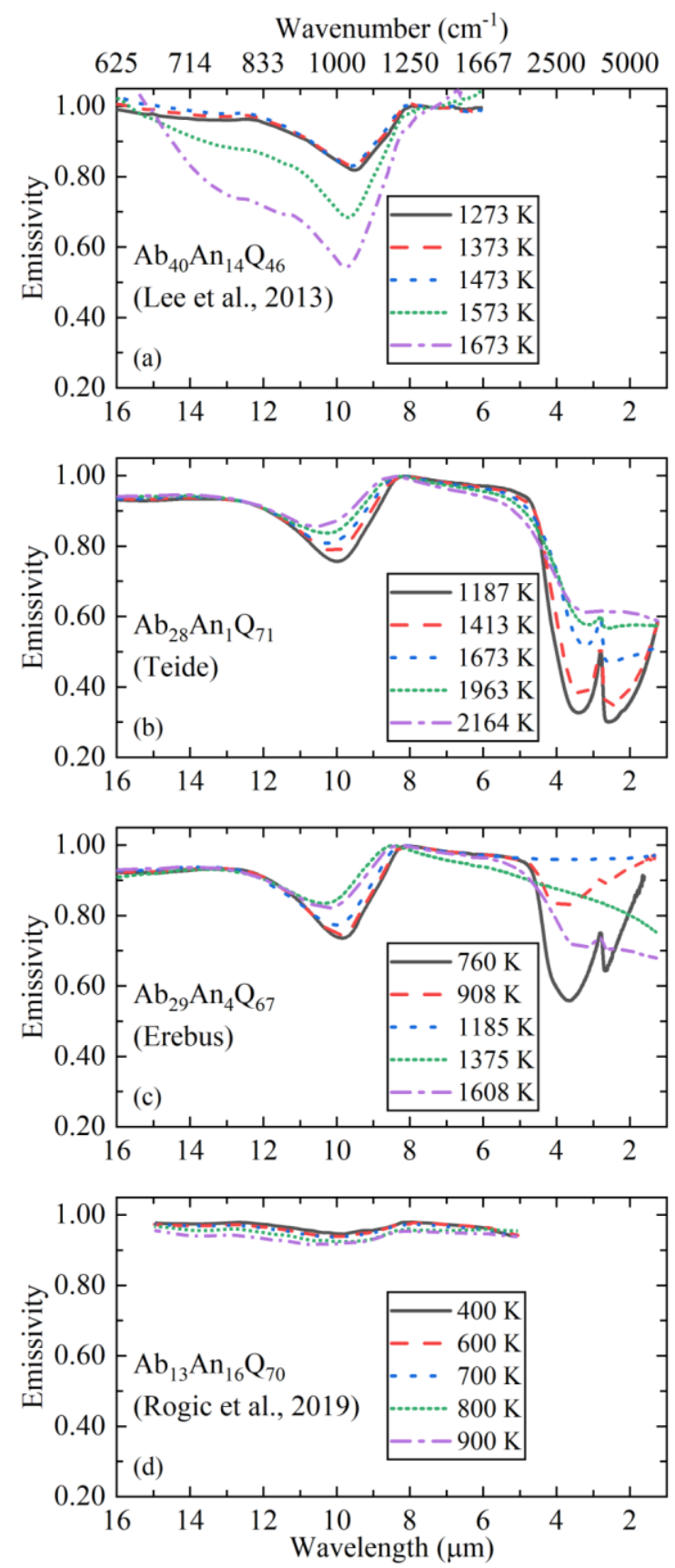

Fig. 8. Comparison of temperature dependences of spectral emissivity reported in previous works (a, d) [8], [13], and in this study $(b, c)$. 

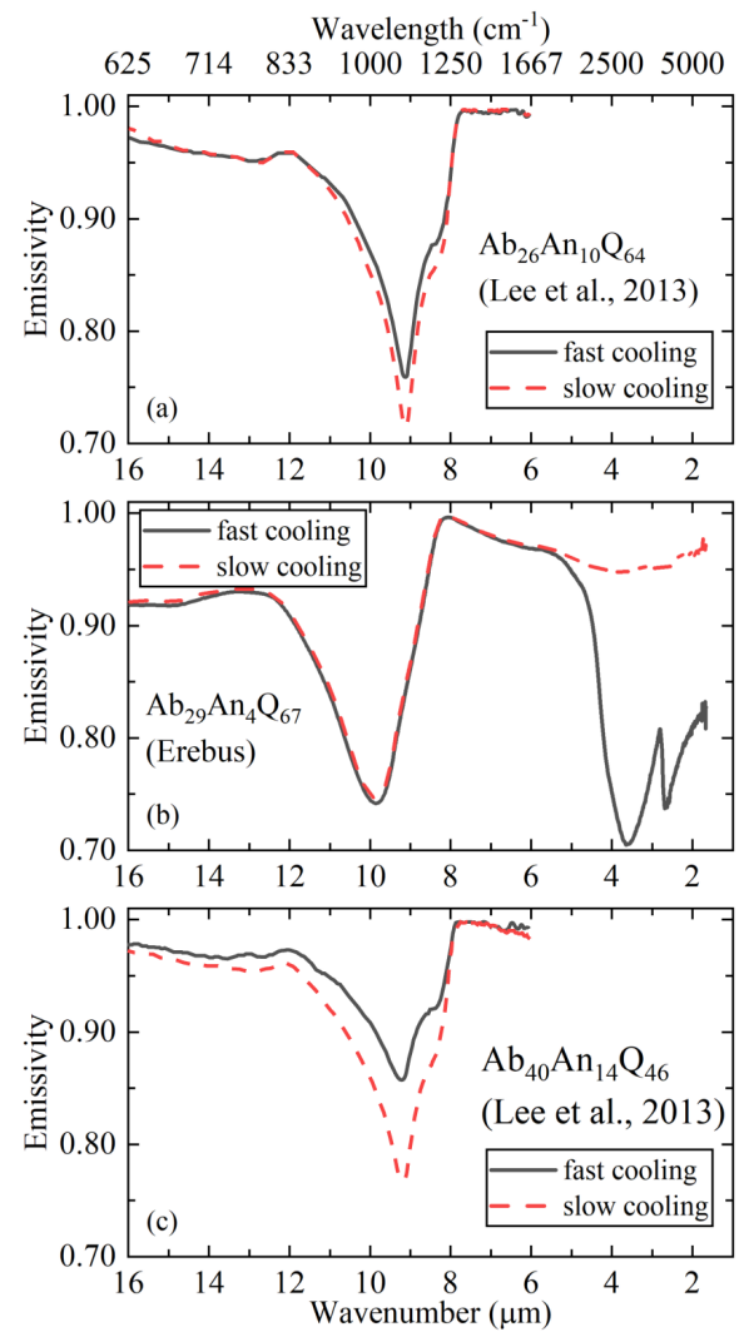

Fig. 9. Comparison of spectral emissivity recorded after slow or fast cooling (quench) in previous work (panels a,c) [8], and in this study (b). 

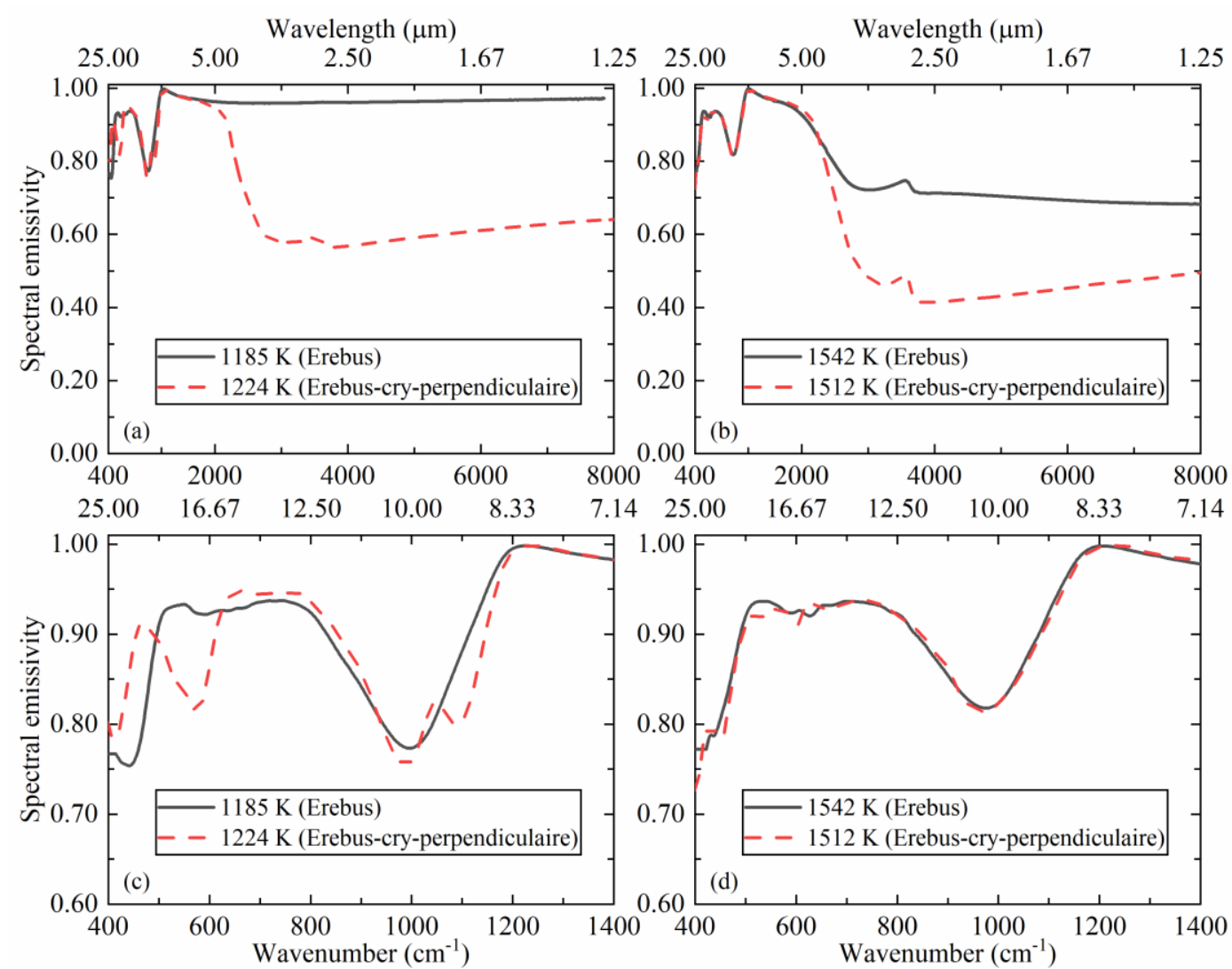

Fig. 10. Comparison of spectral emissivity between anorthoclase crystal and Erebus glass samples around 1200K (a, c) and $1500 \mathrm{~K}(\mathrm{~b}, \mathrm{~d})$. 


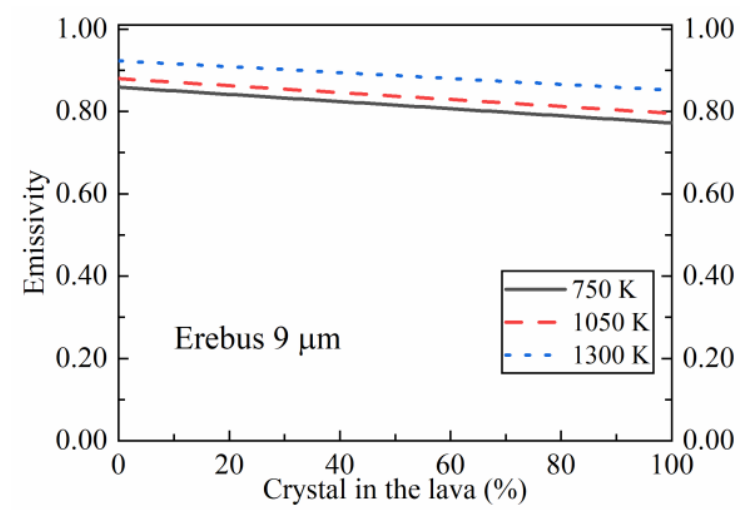

Fig. 11. The impact of crystal content on the total magma Erebus emissivity as a function of temperature, calculated for the wavelength at $9 \mu \mathrm{m}$. 


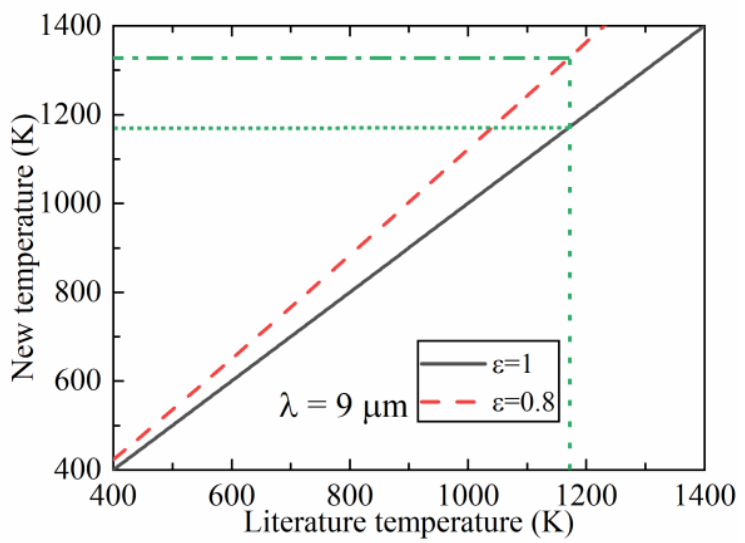

Fig. 12. Impact of change in emissivity (from 1 to 0.8 ) on retrieved temperature in the $9 \mu \mathrm{m}$ TIR region for the Erebus phonolite. 
List of tables:

Table 1. Chemical compositions (wt\%) with standard deviation of Teide and Erebus samples.

Table 2. Refined Erebus temperatures using the measured emissivity values determined in this work and considering the crystal content of $30 \mathrm{wt} \%$. 
TABLE I

CHEMICAL COMPOSITIONS (WT\%) WITH STANDARD DEVIATION OF TEIDE AND EREBUS SAMPLES

\begin{tabular}{cccc}
\hline & Teide $(\mathrm{n}=40)$ & Erebus $(\mathrm{n}=40)$ & $\begin{array}{c}\text { Erebus crystal } \\
(\text { melted, } \mathrm{n}=40)\end{array}$ \\
\hline $\mathrm{SiO}_{2}$ & $61.61 \pm 0.27$ & $56.56 \pm 0.32$ & $62.25 \pm 0.67$ \\
$\mathrm{Al}_{2} \mathrm{O}_{3}$ & $18.58 \pm 0.17$ & $19.28 \pm 0.18$ & $21.62 \pm 0.28$ \\
$\mathrm{Na}_{2} \mathrm{O}$ & $8.70 \pm 0.18$ & $9.44 \pm 0.14$ & $8.13 \pm 0.32$ \\
$\mathrm{~K}_{2} \mathrm{O}$ & $5.53 \pm 0.13$ & $4.60 \pm 0.15$ & $3.38 \pm 0.23$ \\
$\mathrm{CaO}$ & $0.84 \pm 0.04$ & $2.68 \pm 0.06$ & $3.27 \pm 0.43$ \\
$\mathrm{FeO}$ & $3.32 \pm 0.21$ & $5.11 \pm 0.29$ & $0.90 \pm 0.29$ \\
$\mathrm{MgO}$ & $0.45 \pm 0.03$ & $0.90 \pm 0.03$ & $0.15 \pm 0.04$ \\
$\mathrm{TiO}_{2}$ & $0.70 \pm 0.10$ & $0.94 \pm 0.09$ & $0.22 \pm 0.12$ \\
$\mathrm{MnO}$ & $0.19 \pm 0.10$ & $0.21 \pm 0.11$ & $0.05 \pm 0.05$ \\
$\mathrm{P}_{2} \mathrm{O}_{5}$ & $0.08 \pm 0.06$ & $0.28 \pm 0.11$ & $0.03 \pm 0.04$ \\
$\mathrm{Total}^{a}$ & 100 & 100 & 100 \\
$\mathrm{AbAnQ}$ & $\mathrm{Ab}_{28} \mathrm{An}_{1} \mathrm{Q}_{71}$ & $\mathrm{Ab}_{29} \mathrm{An}_{4} \mathrm{Q}_{67}$ & $\mathrm{Ab}_{23} \mathrm{An}_{4} \mathrm{Q}_{73}$ \\
\hline
\end{tabular}

${ }^{a}$ calculated in mol\%, normalized to $100 \%, \mathrm{Ab}=(\mathrm{Na}+\mathrm{K}) /(\mathrm{Na}+\mathrm{K}+\mathrm{Ca}+\mathrm{Si})$; $\mathrm{An}=(\mathrm{Ca}) /(\mathrm{Na}+\mathrm{K}+\mathrm{Ca}+\mathrm{Si}) ; \mathrm{Q}=(\mathrm{Si}) /(\mathrm{Na}+\mathrm{K}+\mathrm{Ca}+\mathrm{Si})$.

${ }^{b}$ Erebus crystal (melted) is a fully melted anorthoclase feldspar. 
TABLE 2

REFINED EREBUS TEMPERATURES USING THE MEASURED EMISSIVITY VALUES DETERMINED IN THIS WORK AND CONSIDERING THE CRYSTAL CONTENT OF $30 \mathrm{WT} \%$.

\begin{tabular}{|c|c|c|c|c|c|c|c|}
\hline & \multicolumn{2}{|c|}{$2.5 \mu \mathrm{m}[29]$} & \multicolumn{3}{|c|}{ 3.6-5.0 um [31] } & \multicolumn{2}{|c|}{$7.5-13 \mu \mathrm{m}[29]$} \\
\hline $\mathrm{T}_{\text {literature }}(\mathrm{K})$ & 907 & 995 & $\begin{array}{l}1174 \text { (Ray lake } \\
\text { max. surface T) }\end{array}$ & $\begin{array}{c}1196 \text { (Werner lake } \\
\text { max. surface T) }\end{array}$ & $\begin{array}{c}773 \text { (daily average } \\
\text { Werner T) }\end{array}$ & $\begin{array}{l}1090(\max . \\
\text { surface T) }\end{array}$ & $\begin{array}{c}807 \\
\text { (effective T) }\end{array}$ \\
\hline$\varepsilon_{\text {literature }}$ & 0.96 & 0.96 & 1 & 1 & 1 & 0.96 & 0.96 \\
\hline$\varepsilon_{\text {this study }}$ & 0.955 & 0.955 & 0.955 & 0.955 & 0.955 & 0.890 & 0.883 \\
\hline $\mathrm{T}_{\text {this study }}(\mathrm{K})$ & 908 & 996 & 1188 & 1210 & 782 & 1110 & 824 \\
\hline$\Delta \mathrm{T}(\mathrm{K})$ & 1 & 1 & 14 & 14 & 9 & 20 & 17 \\
\hline
\end{tabular}

